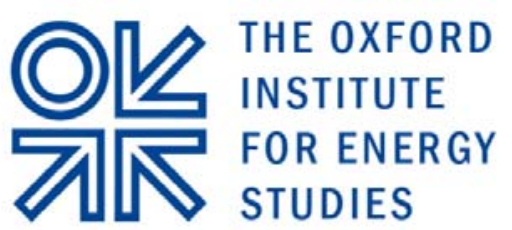

A RECOGNIZED INDEPENDENT CENTRE OF THE UNIVERSITY OF OXFORD

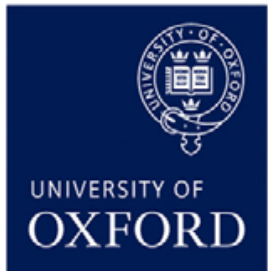

\title{
Assessing the Financialization Hypothesis
}

\section{Bassam Fattouh $^{1}$ and Lavan Mahadeva ${ }^{2 *}$}

WPM 49

November 2012

\footnotetext{
${ }^{1}$ Oxford Institute for Energy Studies, University of Oxford. Email: Bassam.Fattouh@oxfordenergy.org 2 Oxford Institute for Energy Studies, University of Oxford. Email: lavan.mahadeva@oxfordenergy.org (Corresponding author).

* We would like to thank Galo Nuño and other participants of the joint ECB and Norges Bank Workshop on Monetary Policy and Commodity Prices, 2012, for their helpful comments. The contents of this paper are the authors' sole responsibility.
} 
The contents of this paper are the authors' sole responsibility. They do not necessarily represent the views of the Oxford Institute for Energy Studies or any of its members.

Copyright (C) 2012

\section{Oxford Institute for Energy Studies}

(Registered Charity, No. 286084)

This publication may be reproduced in part for educational or non-profit purposes without special permission from the copyright holder, provided acknowledgment of the source is made. No use of this publication may be made for resale or for any other commercial purpose whatsoever without prior permission in writing from the Oxford Institute for Energy Studies.

ISBN

978-1-907555-61-9 


\begin{abstract}
The main objectives of this paper are to assess whether financialization can impact oil market behaviour over and above structural fundamental changes, and whether these changes affect final consumers' welfare. We build a calibrated macro-finance model of the oil market that solves for the term structure of spot prices and the futures price, as well as consumer welfare. While shifts arising in financial investors' preferences and wealth can explain the rise in participation of purely financial investors, they fail to explain key features such as the movements in the basis. Instead, anticipated changes in the physical layer of the oil market can better explain many of the features often attributed to financialization. We also find that greater financialization has no harmful effects on consumer welfare. Our paper shows that from a regulatory point of view, it is crucial in the first instance to identify the channels through which financialization can result in market failure and then design policies accordingly.
\end{abstract}

JEL-Classification: C63, G12, G13, G17, Q43

Keywords: Oil, Financialization, Macro-finance, Asset Pricing 


\section{Introduction}

One of the most important developments in the oil market in the last ten years has been the greater participation in oil futures and derivatives markets by players such as hedge funds, pension funds, insurance companies, and retail investors, with no business in the production or consumption of the physical product. Financial innovation has lowered the cost of investment in derivatives of commodities and helped these financial players increase their exposure to oil through a wide variety of financial instruments such as futures, options, index funds, exchange traded funds (ETFs), and other bespoke products. This phenomenon has been referred to as the 'financialization' of the oil markets (Tang and Xiong (2010)).

A burgeoning empirical literature links greater financialization to deep changes in oil market behaviour. Among the striking effects attributed to financialization are: a greater volatility of the spot price (Tang and Xiong (2010); Hamilton and Wu (2012)); an increased price comovement between crude oil and financial assets and between crude oil and other non-energy commodities (Silvennoinen and Thorp (2010); Büyükşahin and Robe (2011); the fact that financial players' investment strategies, preferences, degree of risk aversion, and financial constraints can impact futures prices (Acharya, Lochstoer, and Ramadorai (2011); Etula (2009); Singleton (2011)); a breakdown of the relationship between oil prices and inventories (Masters (2008)); and increasing mutual causality between the current spot price, the spot price in the future, and the price for delivery in the future (Hannesson $(2012))$. These empirical findings have triggered concerns among policymakers that the functioning of the oil market has been distorted by greater financialization with adverse consequences on final consumers' welfare.

The main objectives of this paper are to assess whether financialization can impact oil market behaviour over and above structural fundamental changes and whether these changes affect final consumers' welfare. We build a calibrated macro-finance model of the oil market that distinguishes between the physical and financial layers of the oil market 1 The model features oil consumers, financial speculators, and physical speculators (or inventory managers). We assume that financial speculators do not hold physical oil but can bear risk by their ability to hold portfolios of financial instruments and have greater tolerance for risk. Physical speculators trade physical oil and futures contracts under uncertainty. Therefore, in our model we separate physical storage from oil production and separate the writing of oil contracts from production and final consumption. This reflects our assumption that since the breakup of the OPEC

\footnotetext{
${ }^{1}$ See Smith $\sqrt{2009)}$ for a survey of macro-finance models.
} 
administered system in 1986 (Fattouh and Mahadeva (forthcoming)), physical speculators and financial speculators such as swap dealers and investment banks have played a key role in managing the exposure of producers and final consumers to oil price volatility.

This treatment is different from that in the early papers where the typical speculator was assumed to be a physical speculator who sells inventory fully on the forward or futures market. Often this speculator was conflated with the physical producer and it is assumed that the stock is held underground. For example in Hotelling (1931), the rate of inventory release should be such that the difference between the futures price and the current spot price equals interest charges plus storage costs. In these historical expositions, the role of the counterparty to speculators was played by consumers of spot oil, who were called hedgers. Telser (1958), Stein (1987), and recently Hamilton and $\mathrm{Wu}(2012)$ maintain a distinction similar to ours in that there are speculators who do not handle physical commodities. Yet in none of these papers are physical speculators also allowed to partially hedge inventory in the presence of final consumers.

The model also distinguishes between distant and near-term prices of oil. Distant prices can either be probabilistic expectations of the spot price or contracted futures prices. Inventory need not be fully hedged and there is a difference between the expected future spot price and the price of a contract determined now for that future date. Given that part of current production can be stored and the price risk transferred through futures contracts, current developments in demand and supply can affect distant prices. Equally, news of prospective developments can transmit in the opposite direction along the term structure towards the spot price through carry over. Unlike the existing literature, the model allows for the endogenous determination of all three oil market prices (current spot, expected future spot, and the futures price) and the spreads between them (the risk premium, the basis, and expected spot appreciation) to current and future news. Each spread plays a differentiated role in determining the returns of each player. These are all important margins through which structural changes such as financialization can be absorbed.

While welfare played a role in the early literature that discussed the costs and benefits of futures markets (Turnovsky (1983)), the recent literature has not sought to evaluate financialization in normative terms. Whether or not financialization matters is thus left dangerously open. Our paper fills the gap by assessing financialization in terms of its impact on the welfare of final consumers, following an earlier literature on price stabilization and the benefits of futures markets (Newbery and Stiglitz (1981)). The model's design is such that consumers' welfare is 
completely consistent with spot demand for oil: both are derived from the same utility function and prices adjust to clear spot and futures markets. One of the main drivers of welfare is the predictability of consumption. The resulting welfare costs are measured in terms of compensating consumption adjustments to this utility function; in other words what percentage of current and future consumption should be sacrificed relative to the baseline to obtain equivalent utility.

The model is calibrated and numerical results are obtained. While there are papers which have derived some of our predictions algebraically (Acharya, Lochstoer, and Ramadorai (2011), Alquist and Kilian (2010) $)$, there are no other quantitative predictions of financialization which would also enable us to compare them against other structural changes. Even if the predictions are in the right direction, they may be of a minuscule size or better explained by other factors.

We also formalize the financialization hypothesis to generate some quantitative predictions. The first step is to define more precisely what is meant by financialization. In our model, these are shifts to the underlying preferences or constraints on purely financial speculators: first a fall in the risk aversion of financial speculators and, second, a rise in the financial resources they can muster to buy shares or risk-free assets. ${ }^{2}$

As a first control, we simulate a lowering of the risk-free interest rate, which affects both this group and also physical speculators, presumably promoting more risk-taking. This is associated with what has often been described as the search for yield or the risk-taking channel of risk-free rates, which some have suggested might have been responsible for the greater financialization of commodities (Basu and Gavin (2011)). As a further benchmark, we simulate shifts in the physical layer of the oil market: a more expansive net supply and greater uncertainty in supply and demand for physical oil.

The inclusion of these controls allows us to test their predicted effects against those of other changes in the financial or physical layer. They also serve to confirm that there is nothing about our model that precludes consumer welfare from becoming more exposed to changing oil market fundamentals. Thus our work aims to fill the gap identified by Büyükşahin and Robe (2011) who argued that 'additional work is needed, if one is to ascertain whether the impact of financialization represents a welcome improvement in market efficiency or, instead, is a worrisome development.'

There is evidence on all these potential drivers of different oil market behaviour. Bekaert, Hoerova, and Duca (2010) estimate that risk aversion fell during the mid-2000s based on the

\footnotetext{
${ }^{2}$ Future contracts tie up wealth only in so far as they require margin, but nonetheless as expected losses and gains can erode wealth, the amount of resources available might conceivably be thought of financialization.
} 
implied volatility of share prices. There has been an increase in the number of net short contracts taken by non-commercial participants in the WTI futures market, which presumably implies more resources available for investment in oil. Frankel (2006) documents a fall in the benchmark risk-free rates over the same time frame. But at the same time, there have also been massive structural changes in the physical oil market. These include the rapid growth in global oil demand in non-OECD countries driven by industrialization and improvements in levels of income (Kilian and Murphy (2010)), and supply shocks in oil producing countries caused by military conflicts, political instability, and industrial disputes. Furthermore, there has been a general decline in the price responsiveness of oil supply and demand over the latest cycle as consumers have reduced the share of oil in their budgets (Baumeister and Peersman (2011)). Thus there is need for a quantitative model-based methodology to discriminate further.

This matters because the recent empirical work on financialization has taken off without theoretical support. In their survey, Fattouh et al. (2012) find that empirical papers that have found an effect of financialization on recent oil price behaviour have done so within the (admittedly narrow) confines of existing data and feasible techniques. In particular, reduced-form results are not assessed against a coherent mechanism by which financialization shifts can exert important effects. In this paper, we derive and test the hypothesis that because of financialization, the oil price has changed, become less tied to fundamentals and hence oil markets are performing less efficiently in terms of price discovery and risk transfer. We compare this against the implications of other structural changes in the financial or physical layer of oil. This sets the scene by establishing if the reduced-form results can better be generated by the financialization hypothesis or its rivals. While the prediction of financial hypotheses might seem myriad, we are able to narrow these to six sub-hypotheses that the model is able to assess:

- The first claim of the financial hypothesis is that underlying changes in financial speculators' preferences and resources have led to a much greater participation of financial players, and has raised oil price levels (Section 5.1).

- The next argument to be put to the test is that, because of financialization, less inventory is held, price differentials are wider, and current prices are less responsive to future shocks (Section 5.2).

- The third sub-hypothesis is that oil prices have become more sensitive to shocks arising in the financial layer of oil markets, for example in predicted stock market returns (Section 
5.3 .

- The fourth allegation is that financialization has increased the unpredictability of spot oil prices to make the futures price a worse predictor of next-period spot prices (Section 5.4).

- Next, we test if some compensation is needed to keep consumers' utility at the same level as that without financialization and compare this to the welfare effects of other changes (Section 6).

- To complete our study, sixth, we assess the contention that financialization can exacerbate the sensitivity of the welfare of final consumers to shocks (Section 6).

This last aspect is what we think goes closest to the heart of public concerns: not so much whether welfare is affected by greater financialization directly but whether financialization has exposed final consumers brutally to the vagaries of political shocks, to oil spills, and to other uncertainties associated with oil.

We find no support for any aspect of the financialization hypothesis. Financialization in our model is predicted to have little effect on oil market variables and a beneficial effect on final consumers' welfare. In contrast, our numerical results suggest that shifts in the physical layer have much bigger quantitative impacts on key spreads and consumer welfare and can more plausibly explain the recent behaviour of the crude oil market.

The paper is structured as follows. In the next section (Section 2), we present the model, explain some general results and justify the simplifying assumptions. We then go on to assess the data on financialization and oil prices (Section 3). In Section 4 we explain how the model is calibrated and solved. Section 5 presents our tests of the financialization hypothesis. In Section 6] we discuss the results for consumer welfare. Section 7 concludes.

\section{The Model}

The model depicts two periods with three groups of agents. Physical speculators can store oil and either sell it in the future or sell it forward now. It is assumed that they pay the cost of delivery to the final consumer. Financial speculators trade in futures, riskless bonds and risky shares. Consumers only buy in spot markets and producers can only sell in those markets. Futures trading involves paying a stochastic transaction cost. Storing oil incurs a fixed per unit 
cost of carry but there is a convenience yield. In what follows all lower case variables denote logs.

\subsection{Physical speculators}

The financial decision of speculators is modelled as in Campbell, Chan, and Viceira (2003). The physical speculators' objective is to maximize a power utility function in their next period wealth:

$$
U_{r, 1}=\mathbb{E}_{0}\left[\frac{\left(W_{r, 1}\right)^{1-\tau_{r}}}{1-\tau_{r}}\right]
$$

with wealth in period $s$ denoted by $W_{r, s}$. Wealth evolves according to:

$$
W_{r, 1}=W_{r, 0}\left(\left(1-\alpha_{r 1,0}-\alpha_{r 2,0}\right)\left(1+r_{f}\right)+\alpha_{r 1,0} \frac{P_{1} C_{q 1,1}}{P_{0}}+\alpha_{r 2,0} \frac{F_{0}^{1} C_{q 2,1}}{P_{0}}\right)
$$

where $P_{s}$ is the price of oil in period $s(s=0,1)$, and $F_{0}^{1}$ is the price of oil contracted at time 0 to be delivered at time 1 .

$\alpha_{r 1,0}+\alpha_{r 2,0}$ is the share of wealth spent on purchasing oil to store in physical inventory while $\frac{\alpha_{r 2,0}}{\alpha_{r 1,0}+\alpha_{r 2,0}}$ is the share of carry over value sold forward (also called the hedge ratio). In the extreme case that $\alpha_{r 1,0}=0$ and $\alpha_{r 2,0}=1$, all wealth is invested in oil and the entire value of carry over is hedged, such that the gross return will be $\frac{F_{0}^{1} C_{q 2,1}}{P_{0}\left(1+r_{f}\right)}$. The physical speculator cannot take a position unbacked by physical quantities. The rest of wealth is invested in bonds earning a risk-free rate of $r_{f}$.

The variables $C_{q 1,1}$ and $C_{q 2,1}$ play important roles in helping our model match the available data on spreads. One common component of both is the cost of delivering oil to the sale destination, which we assume is the responsibility of the physical speculator. Another common component is the net convenience yield payment, an extra return on having physical oil. We assume the final buyer pays for the convenience yield to the physical speculator through the intermediary, net of storage costs. The larger the likelihood of very high prices in the next period, the greater the likelihood of a disruption and the greater the convenience yield payment. Thus this yield is a function of the distribution of the next-period price level as well as a trigger price, and this matters in determining the response of spreads to structural changes. There is also a stochastic proportionate transaction cost for writing short futures contracts. In log terms, this is equal to the mean $\log$ return to shares $\left(\mathbb{E}_{0} \ln R_{e, 1}\right)$ minus the log of the cost paid by those 
going long $\left.\left(c_{g, 1}\right)\right]^{3}$ In log terms, we write $C_{q 1,1}$ and $C_{q 2,1}$ as:

$$
\begin{aligned}
c_{q 1,1} & =\bar{c}_{q 1}+\varrho \operatorname{erob}\left(P_{1}>P^{*}\right) \\
c_{q 2,1} & =\bar{c}_{q 1}+\varrho \operatorname{erob}\left(P_{1}>P^{*}\right)-c_{g, 1}+\mathbb{E}_{0} \ln R_{e, 1}
\end{aligned}
$$

where the probability of a price level greater than the trigger price $P^{*}$ (where $P^{*}>\mathbb{E}_{0}\left[P_{1}\right]$ ) is $\operatorname{prob}\left(P_{1}>P^{*}\right)=\operatorname{prob}\left(p_{1}>p^{*}\right)=1-\phi\left(\frac{p^{*}-\mathbb{E}_{0}\left[p_{1}\right]}{\operatorname{Var}_{0}\left[p_{1}\right]^{0.5}}\right)$ using the standard normal cumulative distribution $\phi($.$) . \varrho$ is the elasticity of the convenience yield. In principle, we could have allowed for different elasticities between the unhedged and hedged storage but in our calibrations, the values turned out to be similar. $\bar{c}_{q 1}$ is the delivery cost in log terms $4^{4}$

Proposition 2.1. The solution to the physical speculators' problem of maximizing 1 subject to 2. by choice of $\alpha_{r 1,0}$ and $\alpha_{r 2,0}$ is approximately given by:

$$
\begin{aligned}
& \boldsymbol{\alpha}_{r, 0}^{T}=\frac{1}{1+\tau_{r}} \\
& \times\left(\mathbb{E}_{0}\left[\mathbf{r}_{r s, 1}\right]-r_{f} \iota+\frac{1}{2} \operatorname{diag}\left(\operatorname{Var}_{0}\left[\mathbf{r}_{r s, 1}\right]\right)+\frac{1}{2} \operatorname{diag}\left(\left[\mathbb{E}_{0}\left[\mathbf{r}_{r s, 1}\right]-r_{f} \boldsymbol{\iota}\right]\left[\mathbb{E}_{0}\left[\mathbf{r}_{r s, 1}\right]-r_{f} \iota\right]^{T}\right)\right) \\
& \times\left(\operatorname{Var}_{0}\left[\mathbf{r}_{r s, 1}\right]+\left[\mathbb{E}_{0}\left[\mathbf{r}_{r s, 1}\right]-r_{f} \boldsymbol{\iota}\right]\left[\mathbb{E}_{0}\left[\mathbf{r}_{r s, 1}\right]-r_{f} \boldsymbol{\iota}\right]^{T}\right)^{-1}
\end{aligned}
$$

where

$$
\begin{gathered}
\boldsymbol{\alpha}_{r, 0} \equiv\left[\begin{array}{c}
\alpha_{r 1,0} \\
\alpha_{r 2,0}
\end{array}\right] \\
\mathbf{r}_{r s, 1} \equiv\left[\begin{array}{c}
p_{1}+c_{q 1,1}-p_{0} \\
f_{0}^{1}+c_{q 2,1}-p_{0}
\end{array}\right]
\end{gathered}
$$

$\operatorname{diag}(\boldsymbol{A})$ signifies a vector made of the elements of matrix $\boldsymbol{A}$ and $\iota \equiv[1,1]$.

Proof. See appendix A.

\footnotetext{
${ }^{3}$ This is needed because we are going to initiate the numerical solutions around a point where there must be some benefit in that state of engaging in the futures trade for both parties. Thus, the mean value of the log on that cost of going short is set such that the gross returns to all activities (holding hedged physical inventory, holding unhedged inventory, financial speculation on futures, and investing at the risk-free rate) are all close to each other. Another interpretation is that the provider of the futures services earns a mean log return close to the mean log return on shares.

${ }^{4}$ In this analytically convenient specification, the parameters that determine the consequences of an extreme price for final consumers or the possibility of hitting a lower bound on physical storage are implicit. See references to and the criticism of the ad hoc convenience yield in Pirrong (2012). Yet in our experiments, we do not alter these parameters and our results are robust to this assumption. We assume the convenience yield payment passed on to physical speculators matches exactly the benefit of convenience it affords, so that the convenience yield does not enter consumers' welfare in net terms and so does not distort our results on welfare.
} 
The amount of carry over is related to the value invested:

$$
Q_{0}=\frac{W_{r, 0}\left(\alpha_{r, 1}+\alpha_{r, 2}\right)}{P_{0}}
$$

As shall be shown below, a supply of storage services function follows from substituting the first-order condition (4) into expression (5).

\section{$2.2 \quad$ Financial Speculators}

Financial speculators have no capacity to hold inventory. This means that they expect to gain from the difference between the spot price on maturity of the futures contract and the contract price. It also means that at time 0 they do not have to sacrifice any wealth to enter into this futures contract. This return is adjusted for by the non-stochastic cost of trading, which is proportional to the value of the futures contracts. They also earn a gross return of $R_{e, 1}$ from other investments in shares. Futures transactions earn an additional stochastic element. Speculators can earn a return of futures transactions if $C_{g, 1}>1$, and this would be the return on margin. If $C_{g, 1}<1$, this is a cost. Thus their objective is to maximize

$$
U_{s, 1}=\mathbb{E}_{0}\left[\frac{\left(W_{s, 1}\right)^{1-\tau_{s}}}{1-\tau_{s}}\right]
$$

subject to a budget constraint,

$$
W_{s, 1}=W_{s, 0}\left(\left(1-\alpha_{s 2,0}\right)\left(1+r_{f}\right)+\alpha_{s 1,0} \frac{P_{1} C_{g, 1}}{F_{0}^{1}}+\alpha_{s 2,0} R_{e, 1}\right)
$$

where wealth in period 1 denoted by $W_{s, 1}, \alpha_{s 2,0}$ is the share of wealth held in risky equity as opposed to riskless bonds and $\alpha_{s 1,0}$ is the value of the futures commitment in terms of period 0 wealth. $\alpha_{s 1,0}$ is not a share, as a futures position is essentially a bet rather than an investment.

Proposition 2.2. The solution to the financial speculators' problem of maximizing 6 subject to 7 by choice of $\alpha_{s 1,0}$ and $\alpha_{s 2,0}$ is approximately given by:

$$
\begin{aligned}
& \frac{1}{\left(1+\alpha_{s 1,0}\right)} \boldsymbol{\alpha}_{s, 0}^{T}=\frac{1}{1+\tau_{s}} \\
& \left(\mathbb{E}_{0}\left[\mathbf{r}_{s s, 1}\right]-r_{f} \iota+\frac{1}{2} \operatorname{diag}\left(\operatorname{Var}_{0}\left[\mathbf{r}_{s s, 1}\right]\right)+\frac{1}{2} \operatorname{diag}\left(\left[\mathbb{E}_{0}\left[\mathbf{r}_{s s, 1}\right]-r_{f} \iota\right]\left[\mathbb{E}_{0}\left[\mathbf{r}_{s s, 1}\right]-r_{f} \iota\right]^{T}\right)\right) \\
& \times\left(\operatorname{Var}_{0}\left[\mathbf{r}_{s s, 1}\right]+\left[\mathbb{E}_{0}\left[\mathbf{r}_{s s, 1}\right]-r_{f} \iota\right]\left[\mathbb{E}_{0}\left[\mathbf{r}_{s s, 1}\right]-r_{f} \iota\right]^{T}\right)^{-1}
\end{aligned}
$$


where

$$
\boldsymbol{\alpha}_{s, 0} \equiv\left[\begin{array}{c}
\alpha_{s 1,0} \\
\alpha_{s 2,0}
\end{array}\right]
$$

and

$$
\mathbf{r}_{s s, 1} \equiv\left[\begin{array}{c}
p_{1}+c_{g, 1}-f_{0}^{1} \\
r_{e, 1}
\end{array}\right]
$$

Proof. See appendix A.

\subsection{The Spot Market}

The objective of final consumers is to maximize their utility from consumption over both periods

$$
U\left(C_{c, 0}\right)+\beta \mathbb{E}_{0} U\left(C_{c, 1}\right)
$$

where $\beta$ is the discount rate and it is assumed that each period's utility is of the power form,

$$
U(z)=\frac{(z)^{1-\chi}-1}{1-\chi}
$$

and that total consumption $C_{c, s}$ is a CES aggregate of the consumption of purchases of spot oil $\left(X_{s}\right)$ and other items $\left(Y_{s}\right)$,

$$
C_{c, s}=\lambda_{s}\left[\Gamma_{s}^{\frac{1}{\omega}}\left(X_{s}\right)^{\frac{\omega-1}{\omega}}+\left(Y_{s}\right)^{\frac{\omega-1}{\omega}}\right]^{\frac{\omega}{\omega-1}}
$$

with $\lambda_{s} \equiv\left(\frac{1}{1+\Gamma_{s}^{\frac{1}{\omega}}}\right)^{\frac{\omega-1}{\omega}}$ for $s=1,2$.

The consumers' demand for oil in each period is then

$$
X_{s}=Y_{s} \Gamma_{s} P_{s}^{-\omega}
$$

with $P_{s}$ being the real price of oil in terms of the price of the other items.

The total demand for spot oil is an aggregate of consumer demand and physical speculators' 
carry over䣕

$$
D_{0}=X_{0}^{\varsigma} Q_{0}^{1-\varsigma} \text { and } D_{1}=X_{1}^{\varsigma}\left(Q_{0}\right)^{-(1-\varsigma)}
$$

The supply of oil combining exploration and extraction is given by a simple function 7

$$
O_{s}=G_{s} P_{s}^{\theta}
$$

Equating demand and supply at periods 0 and 1 and rearranging we have:

$$
P_{0}=A_{0} \Delta_{0} Q_{0}^{\eta} \text { and } \mathbb{E}_{0} Y_{1}^{\varsigma} \Gamma_{1}^{\varsigma} P_{1}^{-\omega \varsigma} Q_{0}^{-(1-\varsigma)}=\mathbb{E}_{0} G_{1} P_{1}^{\theta} \Rightarrow P_{1}=A_{1} \Delta_{1} Q_{0}^{-\eta}
$$

where $\eta \equiv \frac{1-\varsigma}{\theta+\omega \varsigma}, \Delta_{s} \equiv G_{s}^{-\frac{1}{\theta+\omega \varsigma}} Y_{s}^{\frac{\varsigma}{\theta+\omega \varsigma}}$ and $A_{s} \equiv \Gamma_{s}^{\frac{\varsigma}{\theta+\omega \varsigma}}$. The spot price of oil $\left(P_{s}\right)$ depends on the evolution of taste $\left(\Gamma_{s}\right)$, an exogenous supply and demand shock $\left(G_{s}\right.$ and $\left.Y_{s}\right)$, as well as the amount taken out of circulation in period 0 and released in $1\left(Q_{0}\right)$.

In order for the futures markets to clear it must be that

$$
W_{r, 0} \alpha_{r 2,0}=W_{s, 0} \alpha_{s 1,0}
$$

while the physical inventory market settles according to equation (5).

\subsection{Stochastic Processes}

$Y_{1}, G_{1}, R_{e, 1}$ and $C_{g, 1}$ are log-normally distributed such that

$$
\begin{aligned}
& y_{1}=\rho_{y} y_{0}+\left(1-\rho_{y}\right) \mu_{y, 1}+e_{y, 1} \\
& g_{1}=\rho_{g} g_{0}+\left(1-\rho_{g}\right) \mu_{g, 1}+e_{g, 1} \\
& c_{g, 1}=\mu_{c g}+e_{c g, 1} \text { and } \\
& r_{e, 1}=\rho_{r, e} r_{e, 0}+\left(1-\rho_{r}\right) \mu_{r e, 1}+e_{r e, 1}
\end{aligned}
$$

\footnotetext{
${ }^{5}$ Strictly speaking, the price of carry over should be distinguished from that received by producers according to $P_{r, s}=P_{o, s}^{\frac{1}{1-\varsigma}} P_{s}^{-\frac{\varsigma}{1-\varsigma}}$ since final demand and carry over are not perfect substitutes. But as it would complicate the presentation to have different prices we assumed that both of these are equal to the final consumer's price. This assumption would be consistent if physical speculator demand and final consumer demand were in a fixed proportion: $\frac{X_{s}}{D_{s}}=\frac{\varsigma}{1-\varsigma}$.

${ }^{6}$ In contrast to seminal papers by Gustafson (1958), Deaton and Laroque (1996), and Pirrong (2012), we do not impose the condition that inventory can be non-negative. This is not because we do not think that this condition is unimportant or unrealistic but rather that we do not think that it affects our main results concerning welfare. Allowing for this constraint into our analysis would substantially complicate our numerical solution technique. In some sense this is captured by the convenience yield terms.

${ }^{7}$ This can be replaced by any model of spot oil supply. For example we could incorporate the possibility of exhaustibility, extraction costs, and monopolistic or collusive behaviour.
} 
where $\mathbf{e}_{1} \equiv\left[e_{y, 1}, e_{g, 1}, e_{r e, 1}, e_{c f, 1}\right]$ is a vector of normally distributed processes with zero means and respective variances, $\left[\sigma_{y}^{2}, \sigma_{g}^{2}, \sigma_{r}^{2}, \sigma_{c g}^{2}\right]$. For simplicity the only non-zero covariance between these processes is between the return on risky assets and world demand $\left(\sigma_{y r e}\right)$.

The unconditional mean values of the logs of $Y_{s}, G_{s}, R_{e, s}$ and $C_{g, s}$ are $\mu_{y, s}, \mu_{g, s}, \mu_{r e, s}$ (for $s=[0,1])$ and $\mu_{c g}$ respectively . All these values are exogenous. The initial values $y_{0}, g_{0}$ and $r_{e, 0}$ in the baseline are set at their initial means but can differ from these values in experiments. The convention is that only variables dated 0 or earlier are known at 0 , the exceptions being $\Gamma_{1}$, $\mu_{y, 1}, \mu_{g, 1}$ and $\mu_{r, 1}$ which are known a period earlier.

In Appendix $\mathrm{B}$ we derive the joint distributions of $P_{1}$ and $R_{e, 1}$; of $X_{1}$ and $D_{1}$; of $p_{1}, y_{1}$ and $x_{1}$, all conditional on time 0 information as well as expressions for $X_{0}$ and $D_{0}$.

\subsection{The Market for Storage}

The model can also be interpreted in terms of the market for storage services. Combining equations 5 and 15 and rearranging gives us the demand for storage services function:

$$
Q_{0}=\left(\frac{\Delta_{0}}{\mathbb{E}_{0}\left[\Delta_{1}\right]} \frac{\mathbb{E}_{0}\left[P_{1}\right]}{P_{0}}\right)^{\frac{1}{2 \eta}}
$$

The storage supply function is more complicated. To begin with, we can substitute for the current price from equation 15 into the clearing of inventory 5 and rearrange to give

$$
Q_{0}=\left(\frac{W_{r, 0}\left(\alpha_{r, 1}+\alpha_{r, 2}\right)}{A_{0} \Delta_{0}}\right)^{\frac{1}{1+\eta}}
$$

According to the physical speculators' optimizing condition (4) the supply of carry over is an increasing function of both the expected appreciation and the inverted basis: $\frac{\mathbb{E}_{0}\left[P_{1}\right]}{P_{0}}$ and $\frac{F_{0}^{1}}{P_{0}}$ :

$$
\left(\alpha_{r, 1}+\alpha_{r, 2}\right)=f\left(\ln \left(\frac{\mathbb{E}_{0}\left[P_{1}\right]}{P_{0}}\right), \ln \left(\frac{F_{0}^{1}}{P_{0}}\right)\right)
$$

Matching the short futures (equation (4) for $\alpha_{r, 2}$ ) and long futures positions (equation (8) for $\left.\alpha_{s, 1}\right)$ through futures market clearing (equation (16)), we can associate the inverted basis with expected appreciation:

$$
\ln \left(\frac{F_{0}^{1}}{P_{0}}\right)=g\left(\ln \left(\frac{\mathbb{E}_{0}\left[P_{1}\right]}{P_{0}}\right), \kappa\right)
$$

Financialization parameters (such as financial speculator risk aversion $\tau_{s}$ or resources $W_{s, 0}$ ) are summarized by a typical financialization parameter, $\kappa$. In contrast to most expositions where 
the risk premium plays no role (and where $\frac{\mathbb{E}_{0}\left[P_{1}\right]}{F_{0}^{1}}=1$ ), financialization parameters affect the oil market only through this futures market relationship. Now we substitute for the basis into equation 19 to give

$$
Q_{0}=\left(\frac{W_{r, 0}\left(f\left(\ln \left(\frac{\mathbb{E}_{0}\left[P_{1}\right]}{P_{0}}\right), g\left(\ln \left(\frac{\mathbb{E}_{0}\left[P_{1}\right]}{P_{0}}\right), \kappa\right)\right)\right)}{A_{0} \Delta_{0}}\right)^{\frac{1}{1+\eta}}
$$

Equation 20 is the upward sloping supply of storage function in our simplified market.

The most familiar analogue in the literature to equation (20) is Working (1948)'s supply of storage function according to which, as the inverse of the adjusted basis rises, there is a greater incentive to carry over inventory to the future. But Working allowed other factors to also affect the supply of storage; indeed his main point was that the extent of weak backwardation is not a complete description of the return to fully hedged inventory. There are storage costs and, at low levels of inventory, a convenience yield that also weighs heavily on the incentive to carry over. The question here is whether financialization also can impinge on the supply of storage function so as to reduce the amount of carry over and raise the spread.

\subsection{The Behaviour of Spreads}

Another important feature of the model relates to the general properties of the behaviour of spreads following financialization shifts.

Note first that according to equation (4), the ratio of the values invested by physical speculators in each type of risky asset - hedged and unhedged oil - is independent of their own risk aversion. This separation property does not, however, hold for the financial speculator because their futures position does not take a share in a portfolio (Lioui and Poncet (2005)). Proposition 2.1 is familiar from Campbell, Chan, and Viceira (2003), but proposition 2.2 is, to our knowledge, new.

The internal margin between the hedged and unhedged inventory of physical speculators can, however, adjust to protect physical speculators' returns from shifts in the financial layer. Indeed by manipulating the hedging ratio, physical speculators can achieve returns closer to those of financial speculators. For example, a strategy of buying hedged inventory and selling unhedged inventory with the former at a proportion of $\frac{\mathbb{E}_{0} P_{1}}{F_{0}^{1}}\left(\frac{P_{0}}{F_{0}^{1}}-1\right)$ to the latter will yield a net return of $\frac{\mathbb{E}_{0} P_{1}}{F_{0}^{1}}$ (abstracting from uncertainty or the convenience yield). Thus the physical speculator can reduce his exposure (or even eliminate it) to the spot price at the cost of increasing exposure to 
the financial speculators' expected return. If there is a structural change that affects the spot price but not the risk premium, the physical speculator can immunize themselves such that the amount of inventory they hold will be less affected. There is no possibility for this in models where the futures and the expected spot price are equal such as French (1986) or Alquist and Kilian (2010) 8

Another more general property is highlighted in equation 15, according to which there is an inverse relationship between the term structure of spot prices: a higher carry over must raise the current spot price and lower the expected spot price: $P_{0} P_{1}=A_{1} \Delta_{1} A_{0} \Delta_{0}$. Most importantly, the constant in this relationship (the term $A_{1} \Delta_{1} A_{0} \Delta_{0}$ ) depends only on physical demand and supply forces and is completely independent of any changes in the financial layer. Thus financial shifts can only tilt but not shift the term structure of spot prices, and only raise the expected spot price in so far as they lower the current spot price or vice versa, by the same amount (approximately). Formally we can write this as:

$$
\left.\% \delta \mathbb{E}_{0} P_{1}\right|_{f} \approx-\left.\% \delta P_{0}\right|_{f}
$$

where $\left.\% \delta X\right|_{f}$ indicates the percentage change in $X$ as a consequence of a shift in the financial layer.

This general property contains an important implication for this study. In order for financialization shifts to significantly affect consumers, their welfare must be highly differentially sensitive to twists in the term structure of spot prices. A high differential sensitivity to intertemporal prices, we would confidently argue, does not correspond to a plausible description of what movements in oil prices means to consumers. There is therefore an inherent limit to the policy implications of financialization shifts.

Now consider the relationship between shifts in the risk premium and the basis, both arising from an underlying drive towards greater financialization:

$$
\begin{gathered}
\left.\% \delta \mathbb{E}_{0}\left[P_{1}\right]\right|_{f}-\left.\left.\% \delta F_{0}^{1}\right|_{f} \approx \% \delta P_{0}\right|_{f}-\left.\% \delta F_{0}^{1}\right|_{f}+\left.\% \delta \mathbb{E}_{0}\left[P_{1}\right]\right|_{f}-\left.\% \delta P_{0}\right|_{f} \\
\left.\Rightarrow \% \delta \mathbb{E}_{0}\left[P_{1}\right]\right|_{f}-\left.\% \delta F_{0}^{1}\right|_{f}-\left(\left.\% \delta P_{0}\right|_{f}-\left.\% \delta F_{0}^{1}\right|_{f}\right) \approx-\left.2 \% \delta P_{0}\right|_{f}
\end{gathered}
$$

Thus following a financialization shift, spot prices will only be significantly affected to the

\footnotetext{
${ }^{8}$ The absorbing potential of a portfolio in which unhedged oil is but one asset was discussed in the early literature. See Dusak (1973).
} 
extent that there is a large differential reaction between the risk premium and the basis. This places another limitation on the ability of the financialization hypothesis to both explain the behaviour of spreads and to also be a phenomenon that merits consumer protection.

For the purpose of these arguments, shifts in the risk-free real rate of interest represent shocks to the financial layer as the rate does not enter into the relationship 21. This might be thought to imply a contradiction, as following Hotelling's classic exposition (Hotelling (1931)), we are familiar with the idea that the real risk-free rate represents the cost of carry, and is also present in the physical layer. The contradiction is resolved by an adjustment in the convenience yield in response to shifts in the real rate, which implies much greater sensitivity than predicted by the simple Hotelling rule.

Consider what happens when there is a shift only in the risk-free rate to a version of equation 4 where the expected appreciation adjusted for the convenience yield is equal to the risk-free rate. Then:

$$
\begin{aligned}
& \left.\% \delta \mathbb{E}_{0}\left[P_{1}\right]\right|_{r}-\left.\% \delta P_{0}\right|_{r} \approx \delta r+\left.e_{c q} \% \delta \mathbb{E}_{0}\left[P_{1}\right]\right|_{r} \\
& \left.\Rightarrow \% \delta \mathbb{E}_{0}\left[P_{1}\right]\right|_{r}-\left.\% \delta P_{0}\right|_{r} \approx \delta r+e_{c q} \frac{\left.\% \delta \mathbb{E}_{0}\left[P_{1}\right]\right|_{r}-\left.\% \delta P_{0}\right|_{r}}{2} \\
& \left.\Rightarrow \% \delta \mathbb{E}_{0}\left[P_{1}\right]\right|_{r}-\left.\% \delta P_{0}\right|_{r} \approx \frac{2}{2-e_{c q}} \delta r
\end{aligned}
$$

where the term $e_{c q}$ measures the elasticity of the convenience yield term with respect to the expected spot price, and is positive but less than one. This means that we should in principle expect a aggrandizement of the Hotelling Lemma relationship - that shifts in the real rate are matched by equal shifts in the differential between future and current spot prices. Here we should see a larger response of future-current spot spreads to real rates.

An analogous property won't hold for the inverse basis $\left(\frac{F_{0}^{1}}{P_{0}}\right)$. Following the same logic as above

$$
\begin{aligned}
& \left.\% \delta F_{0}^{1}\right|_{r}-\left.\left.\% \delta P_{0}\right|_{r} \approx \% \delta F_{0}^{1}\right|_{r}-\left.\% \delta \mathbb{E}_{0}\left[P_{1}\right]\right|_{r}+\left.\% \delta \mathbb{E}_{0}\left[P_{1}\right]\right|_{r}-\left.\% \delta P_{0}\right|_{r} \\
& \left.\Rightarrow \% \delta F_{0}^{1}\right|_{r}-\left.\% \delta P_{0}\right|_{r} \approx-\left(\left.\% \delta \mathbb{E}_{0}\left[P_{1}\right]\right|_{r}-\left.\% \delta F_{0}^{1}\right|_{r}\right)+\frac{2}{2-e_{c q}} \delta r
\end{aligned}
$$

The financial risk premium — as a return on a risky investment — should fall as risk-free interest rates are lowered. The first term in the expression above would then act to offset the direct effect on the inverse basis of lower real rates. 


\subsection{The Behaviour of the Final Consumer}

Another point of discussion is our simplifying assumption about consumption behaviour. To clarify, here the amount of other items consumed is determined exogenously, as a stochastic endowment. Given expectations about the relative price of oil and their consumption of other items, consumers choose how much oil to consume. This determines their total consumption, their utility, and welfare. An unpredictable oil price will thus lower their utility.

We could instead have allowed for consumers to adjust total consumption intertemporally through saving, or even through their purchases of oil-consuming capital goods. If intertemporal adjustment were possible, we should consider the first-order conditions for spot oil final consumption at time 1 as,

$$
\Gamma_{1}^{\frac{1}{\omega}} \mathbb{E}_{0}\left[\left(X_{1}\right)^{\frac{-1}{\omega}}\left(C_{c, 1}\right)^{\frac{1}{\omega}}\right]=\mathbb{E}_{0}\left[P_{1}\left(Y_{1}\right)^{\frac{-1}{\omega}}\left(C_{c, 1}\right)^{\frac{1}{\omega}}\right]
$$

and obtain a solution for demand that takes non-linearities into account. Without intertemporal substitution, we can proceed with the linearized solution (12). Intertemporal optimization would also complicate the analysis substantially by making total consumption endogenous.

Does this matter? Intuitively, ruling out consumption smoothing and precautionary saving would mean that we are exaggerating the effects of financialization. As we find the effects to be nonetheless weak, our conclusions will most likely be strengthened by this extension. A similar argument applies to production, where we have also ruled out smoothing.

\section{Evidence on Financialization and Changes in Oil Market Be- haviour}

Chart 1 plots the net long positions of non-commercial traders (excluding swap dealers) in WTI futures markets against the real oil price. We can identify, as others have done, a shift in the average level of participation beginning roughly in 2003. The oil price seems to have risen as financialization has increased. But it is also remarkable that the broad trends of greater financialization and a higher price level were reversed during the second half of 2008, when the severity of the financial crisis became clear.

It is also important to analyse these periods in terms of the triumvirate of spreads that

determine returns to oil market intermediaries: the basis $\left(\frac{P_{0}}{F_{0}^{1}}\right)$, expected appreciation $\left(\frac{\mathbb{E}_{0} P_{1}}{P_{0}}\right)$, 
and the risk premium $\left(\frac{\mathbb{E}_{0} P_{1}}{F_{0}^{1}}\right)$. In Section 2 we saw how these spreads determined the returns to physical and financial speculators.

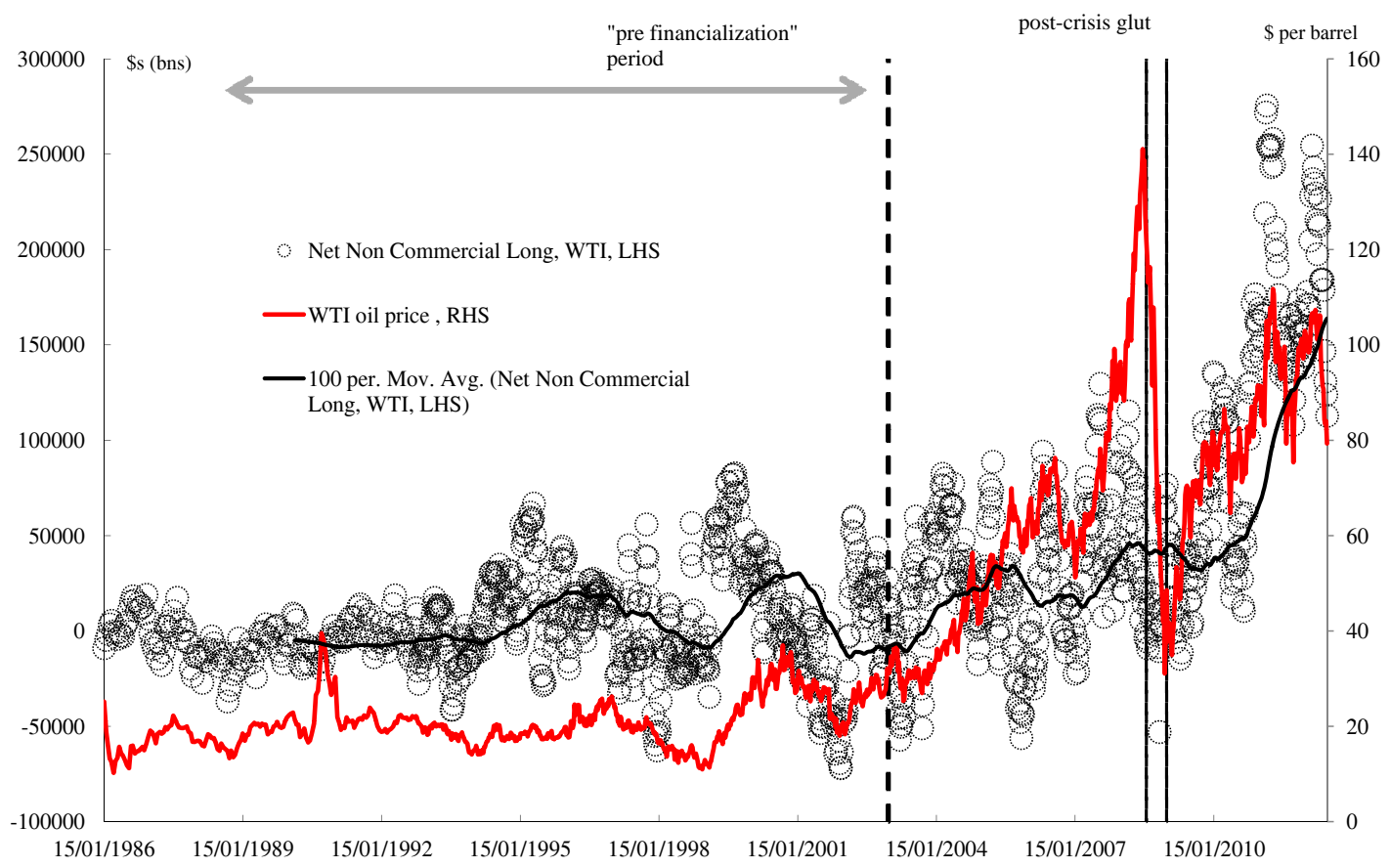

\section{Chart 1: Net long positions of non-commercial traders and the Oil Price ${ }^{a}$}

\footnotetext{
${ }^{a}$ Dark line indicates the 10 month moving average. Source: CTFC reports, St Louis Fed. and own calculations.
}

Chart 2 plots the basis. As we have defined it, the basis is the inverse of the simple return from hedged storage. The complete net excess return would also adjust for the convenience yield, futures participation costs, storage costs, risk premia, and the risk-free rate (the latter as the opportunity cost). Of these excluded components, we can assume that the convenience yield varies the most. In order for there to be no arbitrage, therefore, the basis and the convenience yield must move together, so that the net return to storage is constant. In Chart 2, we can see that the net convenience yield — proxied by the basis — rose up to a peak in 2003 and from then on has declined, interrupted only by a temporary reversal during 2006-2008. These movements in the basis should be explained by an acceptable theory of post- 2003 events. As the basis displays similar behaviour in Brent and WTI, the pattern is not due to the pipeline 
frictions at Cushing (Borenstein and Kellogg (2012)). (Later on we discuss the importance of inventories, also in the chart).

Chart 3 plots the ex-post appreciation of real oil prices - an ex-post measure of the return to unhedged storage enjoyed by the physical speculator. The ex-post appreciation is on average much higher post-2003, but this average is not particularly well determined given the high volatility and the temporary fall in the oil price in 2008. It is hard to conclude much about any shift in expected appreciation.

Chart 4 describes the ex-post return on financial speculation, which is a realization of the unobservable risk premium for purely financial speculators. The ex-post return, though volatile, also appears to be on average higher post-2003. However as Plante and Thies (2012) document a large fall in financial speculators' average annualized oil returns using more appropriate data on commodity indices in the last five years to February 2012, it seems more likely than not that the unobserved risk premium has fallen.9

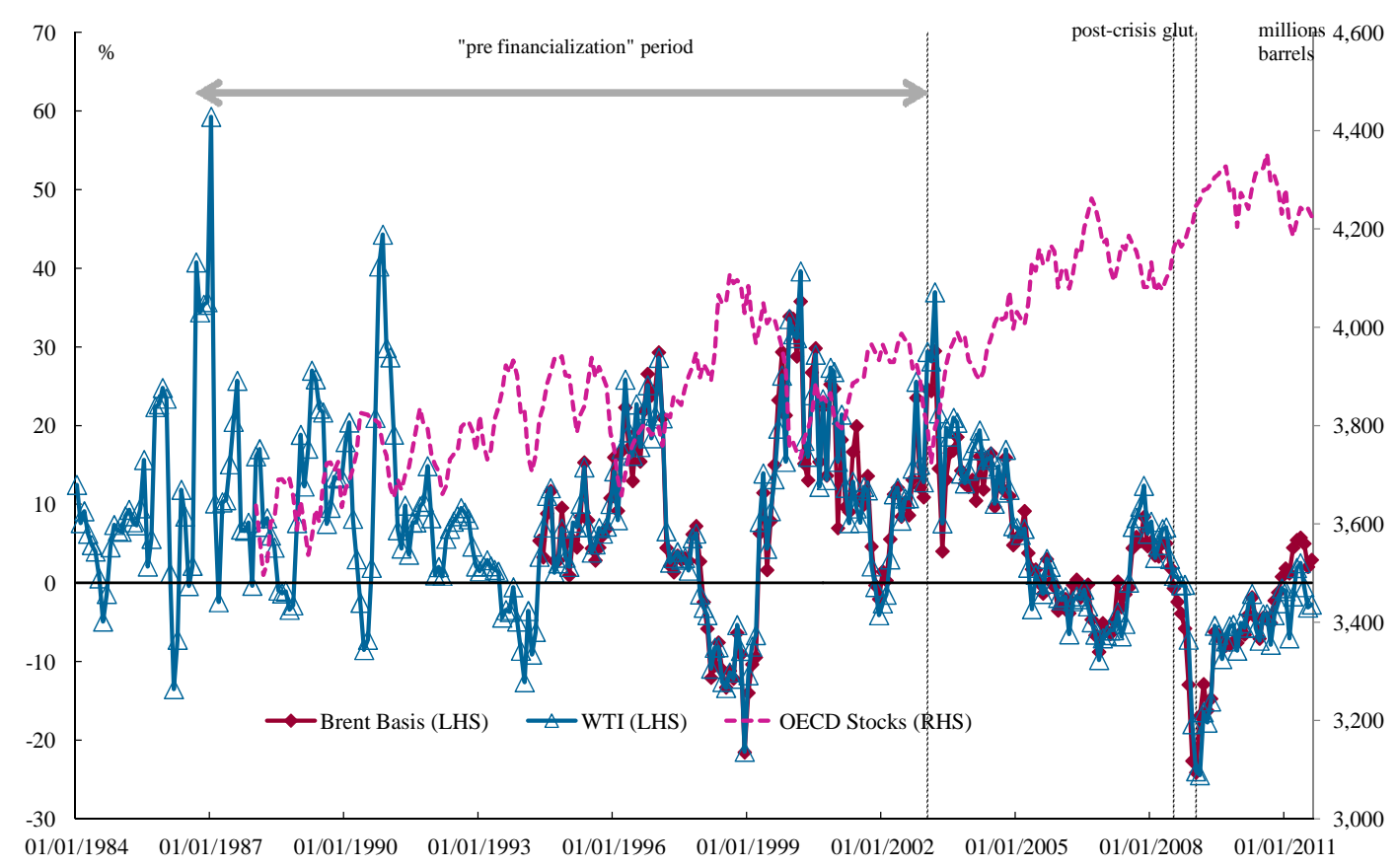

Chart 2: Real Basis (1 mnth versus 12 mnths, arithmetic) ${ }_{a}^{a}$

${ }^{a}$ Source: Bloomberg and own calculations.

${ }^{9}$ See also Hamilton and $\mathrm{Wu}(2012)$. 


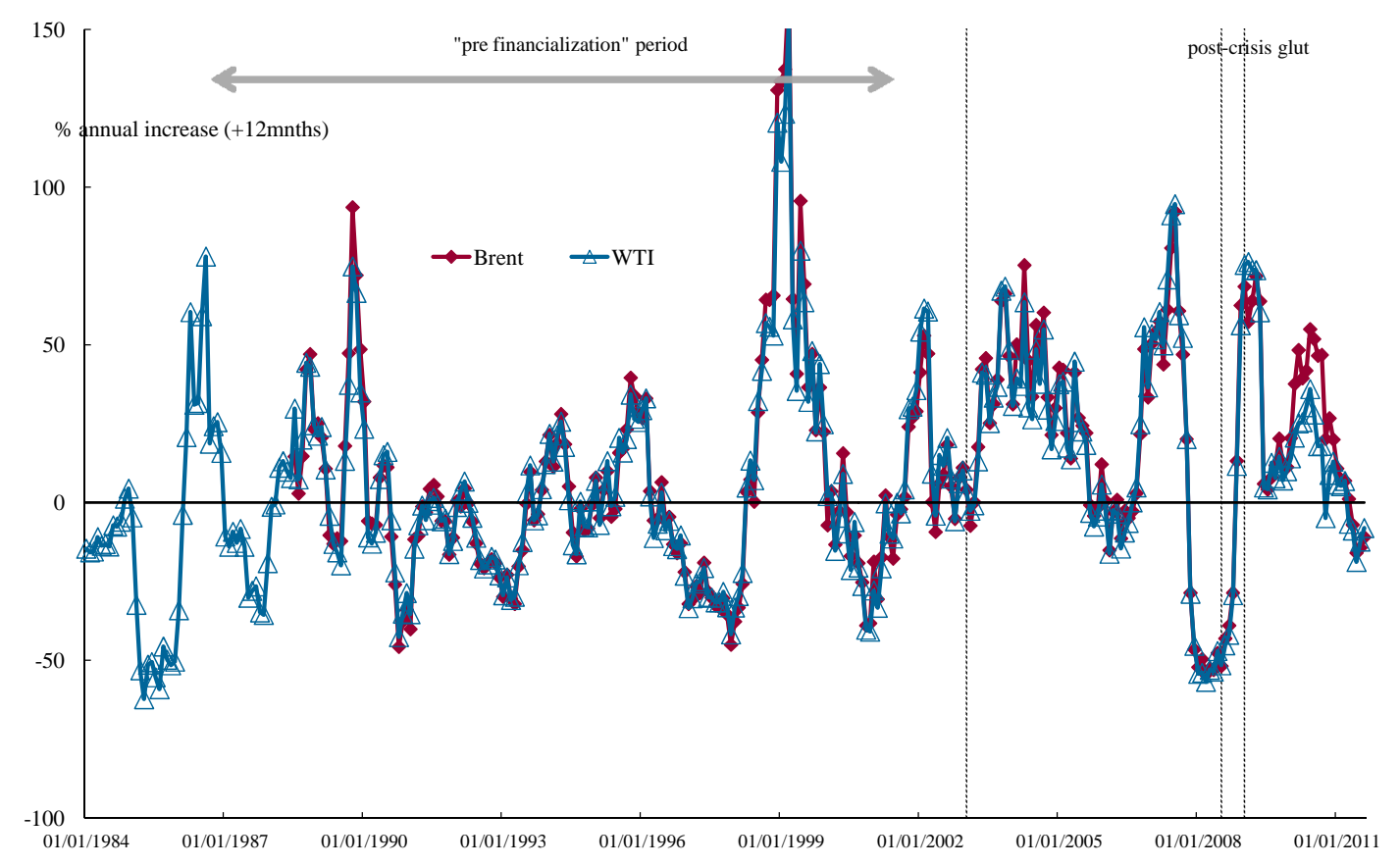

Chart 3: Real Appreciation (12 mnths ahead, arithmetic) ${ }^{a}$

${ }^{a}$ Source: Bloomberg and own calculations

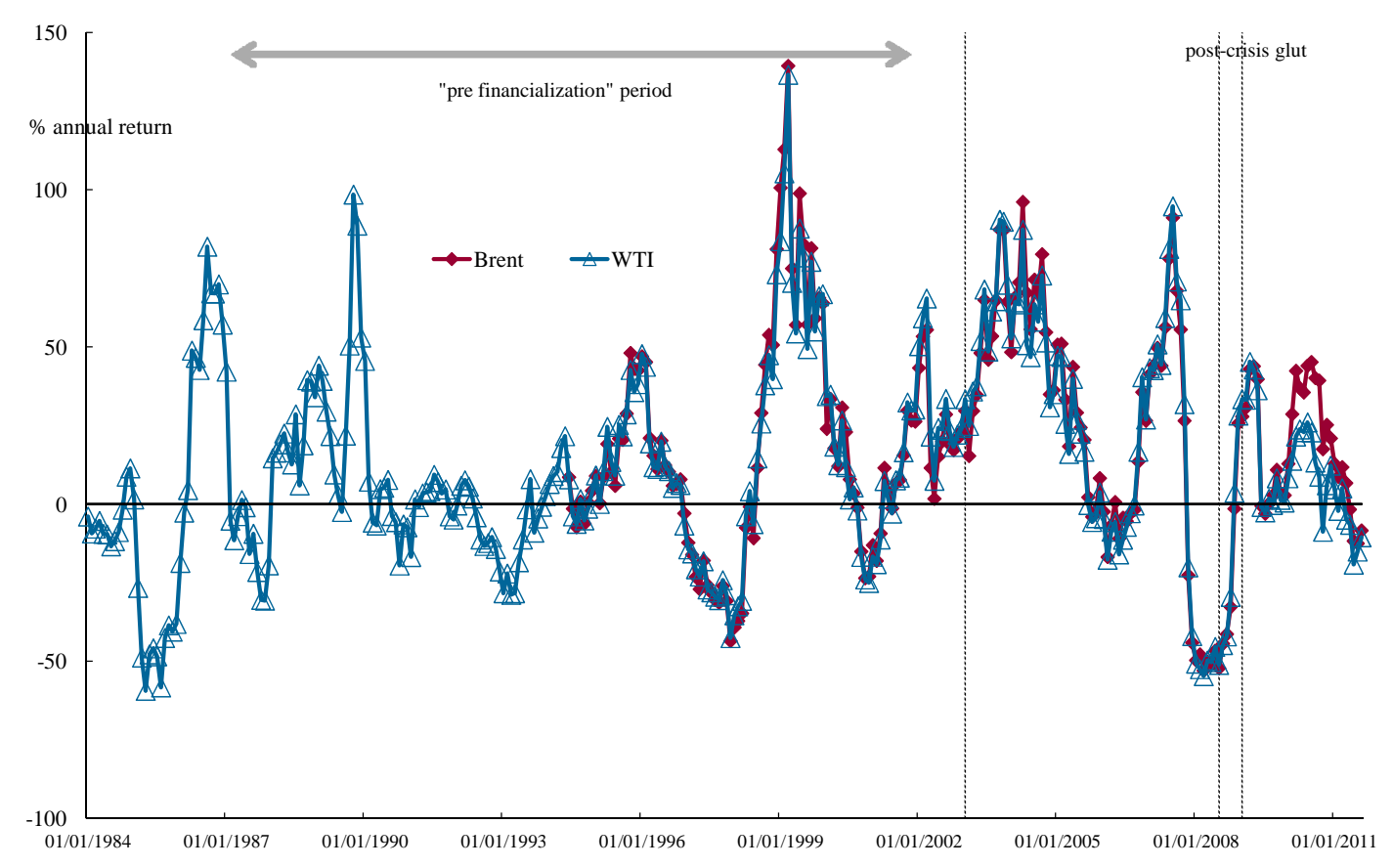

Chart 4: Real Absolute Returns (12 mnths ahead, arithmetic) ${ }^{a}$

${ }^{a}$ Source: Bloomberg and own calculations 
In what follows, we will assume that the value of the net futures position of financial speculators increased after 2003 by a large multiple. Hence we take the period July 1986 to December 2002 to be our baseline, and the period since 2003 to be the era of greater financialization. In market parlance, then, following financialization, oil has gone from market backwardation to having an inverted futures curve. Much more contentiously, we can conclude that appreciation has risen and the extent of average Keynesian backwardation has fallen, but by less than the rise in the basis. The challenge is to establish that these shifts in spreads between the two periods are due to financialization rather than other contending factors or explanations.

Table 1 summarizes the differences in key variables between the pre and post financialization regimes.

Table 1: Behaviour across Different Financialization Regimes.

\begin{tabular}{|l|cc|l|}
\hline Variable & $\begin{array}{c}\text { July } 1986- \\
\text { Dec. 2002 }\end{array}$ & $\begin{array}{c}\text { Jan. 2003 } \\
\text { Jan. 2012 }\end{array}$ & Units \\
\hline Anits \\
\hline Average Real Oil Price & 15.2 & 36.4 & Jan. 1986 \$s \\
Std Devn (Annual) & $4.8 \%$ & $17.5 \%$ & Annualized Average Monthly Arithmetic Increase \\
Average Real Basis & $31.3 \mathrm{pp}$ & $34.4 \mathrm{p}$ & Annual Arithmetic Increase \\
Average Real Convenience Yield & $9.4 \%$ & $1.9 \%$ & Annual Arithmetic Return \\
Average Excess Real Return & $-9.5 \%$ & $-1.1 \%$ & Annual Arithmetic Return \\
Average Real Rate & $13.3 \%$ & $19.2 \%$ & Annual Arithmetic Return \\
Std Devn & $3.5 \%$ & $2.0 \%$ & Annualized Rate \\
\hline
\end{tabular}

Source: St Louis Federal Reserve, own calculations.

Notes : Real values calculated using US CPI excluding food and energy. All oil price data based on the NYMEX WTI futures with the one-month ahead substituting for the current spot price. Treasury Bill Rates at annual maturity for the convenience yield and at a ten year maturity for the Real Rate calculation. Excess returns assume that a 12 month contract is held until just before maturity.

Apart from summarizing our earlier observations on the oil price and the spreads, Table 1 also reports that the unpredictability of oil price appreciation is higher, at least in terms of the 12 month horizon oil price ${ }^{10}$ Note also the long real rate has been significantly lower, in part as a consequence of the 2008 crisis policy actions.

While it should be remembered that these averages mask substantial interperiod variation and non-linearity, these differences seem significant and are echoed in the arguments of those who would link the surging volume of financial flows into the oil market to a different oil market behaviour.

Yet, while this simple comparison admits the possibility that greater financialization leads to a change in oil market behaviour, it certainly does not by itself infer causation. An alternative

\footnotetext{
${ }^{10}$ The monthly oil price volatility has fallen slightly in the period of increased financialization such that in the recent period, the long-horizon volatility is greater than the short-horizon volatility. Recently Pástor and Stambaugh (2012) have shown in the context of equity returns that long-horizon volatility can be greater than its short-run counterpart as the nature of uncertainty overrides mean reversion.
} 
explanation for the different oil price behaviour has little to do with financialization. Kilian and Murphy (2010) and Kilian (2009) have argued convincingly that since 2000, aggregate demand increased strongly and more persistently than before, driving up oil prices. At the end of 2002, oil stocks were low following also a strike in Venezuela, the Gulf war and disruptions in Nigeria (Chart 2). Chart 2 shows that stocks recovered strongly from 2002 until 2006, presumably in anticipation of even stronger demand going forward (Kilian and Murphy (2010)). As we would expect, this drive was accompanied by a fall in the convenience yield (a falling basis). In 2006, demand proved to be so strong that stocks were run down slightly and the convenience yield rose briefly. But in mid-2008, when the financial crisis struck home, the demand for oil fell and stocks accumulated again. As the market suddenly absorbed the implications of the crisis, the oil price fell sharply in the following six months. Steep though it was, the fall in the price level was remarkably short-lived — the level rose back in January 2009 (Chart 1). But the basis returned once more to its prolonged slide: there is little need for convenience during a prolonged recession as long as there are high levels of stocks. Thus it may well be that shifts in the expected supply and demand for crude oil have implied changes in financialization, and not the other way round. It could also be that changes that have occurred in both are largely independent, with financialization having little implication for oil markets.

\section{Calibration and Solution of the Baseline}

Our baseline calibrations are determined by the pre-2003 data. We take the risk-free rate to be 3.5 per cent as this seems consistent with our estimate of the ex-ante long Treasury rate before 2003. The mean and variance of the log returns on equity were set so as to match the mean and variance of arithmetic real returns on the S\&P pre-2003 ( 8.6 per cent and 16.9pp respectively). We did not allow for any autoregression in annual share returns. But we built in a conditional correlation with world demand of 0.2 , in keeping with the data. Judging from data on world GDP, the standard deviation of log demand for oil was 5 per cent and the autoregression at about 0.4. The growth in world demand is set at the growth in world GDP, 5.8 per cent. We set the parameters of risk aversion for physical and financial speculators and also consumers to be at 2. Estimates abound in the literature, but if there is a consensus, it would be at 2 .

The elasticities of oil supply and demand were set at 0.25 and -0.25 respectively. The demand elasticity is close to the median estimate of the use elasticity by Kilian and Murphy 
(2010) that takes account of inventories. The supply elasticity is higher than impact elasticities seen in the literature, but the second period can be interpreted as the long run, where elasticities close this value are common. The other parameters were $\varsigma$, the nominal share of oil taken to inventory relative to sales for final consumption, which we set at 10 per cent. This is meant to roughly approximate the ratio between absolute changes in US commercial and strategic inventories and US final consumption. $\Gamma_{0}\left(=\Gamma_{1}\right)$, the share of oil in consumption in both periods, is set at 5 per cent.

Values for the parameters that describe the convenience yield (in equation 3) are not observable. The storage cost of oil might seem small as a proportion of the oil price. But to this we must add transport costs. Similarly the mean cost of futures transactions (which could even be a positive return if margin is paid) and its variance are not available. We calibrated these parameters to be close to the pre-2003 average estimates of the basis and the risk premium (Table 1). The price trigger for convenience $\left(P^{*}\right)$ was set at two and a half times the mean price in the baseline. The mean and variance of supply were set to match an estimate of the pre-2003 period expected appreciation of the spot price level and its standard deviation. Supply is expected to diminish at a rate of 0.8 per cent.

The model comprising equations $4,5,8,15,16$, and 1 [1] $^{1}$ was solved numerically given these parameters and the starting point ${ }^{12}$ This solution was taken to be the baseline. At the baseline, the basis was 12 per cent, the risk premium 13 per cent and expected appreciation, 1 per cent. The conditional standard deviation of the expected oil price level as a ratio of the level was 41 per cent, just more than the value in Table1. The long futures' position $\left(\alpha_{s, 1}\right)$ was 60 per cent of financial speculator wealth, which was in turn about 36 per cent greater than of that of physical speculators. There was a mean log return on futures transactions for going short of 9 per cent as opposed to a negligible net cost for going long, and the standard deviation of transaction frictions was 3 per cent (all in log terms). The constant reflecting the costs of delivery, $\bar{c}_{q 1}$, was about half of the final price (0.48) while the elasticity on the convenience yield, $\varrho$, was close to 0.15 .

\footnotetext{
${ }^{11}$ Equation 17 and 15 combine to give expressions for the log returns to the speculators. See Appendix $B$.

${ }^{12}$ We started the model close to what we felt were sensible values for the portfolio shares of physical and financial speculators. $1-\alpha_{r, 1}-\alpha_{r, 2}$ is the share of wealth of physical speculators held in risk-free assets which was targeted at 11 per cent, akin to an equity ratio. Their hedging ratio $\left(\frac{\alpha_{r, 2}}{\alpha_{r, 1}+\alpha_{r, 2}}\right)$ was $80 \%$, close to Mexico's 70 per cent hedging of its total reserves. The financial speculators' share of wealth held in risk-free assets $\left(\alpha_{s, 2}\right)$ was $12 \%$, resembling an equity ratio.
} 


\section{$5 \quad$ Testing the Financialization Hypothesis}

We consider three categories of shift: greater financialization, other changes in the financial layer of oil, and changes in the physical layer.

In the first category, we experiment with a fall in the financial speculators' risk aversion $\left(\tau_{s}\right)$ from its baseline value of 2 to 1.5 , and a rise in financial speculators' wealth $\left(W_{s, 0}\right)$ by 25 per cent. We have no evidence on the level of risk aversion let alone how much it has fallen, nevertheless, a fall which puts this parameter halfway towards risk neutrality seems both plausible and substantial. The rise in financial speculators' wealth would be consistent with greater number of financial players in oil financial markets, as broadly suggested by the CTFC data on non-commercials.

In the second category, we include a fall in the risk-free rate $\left(r_{f}\right)$ of $1.5 \mathrm{pp}$ as the long bond rate has been lower in the period of financialization.

The final category examines simulated shifts in the physical layer. We know that the real oil price fell during the mid-2008 glut. Thus we consider a 5 per cent expected loosening in supply (a rise in $\mu_{g, 1}$ ) such that the current oil price would fall by 10 per cent. It also seems that the oil price has been more volatile in the period of greater financialization. This leads us to experiment with a rise in the volatility of supply shocks $\left(\sigma_{g}\right)$ shifting from its baseline value of 8 per cent to 9.3 per cent.

\subsection{The Effect of Financialization on the Long Futures Position and Oil Price}

The first financialization sub-hypothesis is that underlying changes associated with greater participation of financial players has raised oil price levels. Formally we write this as:

$$
\text { Greater financialization } \Rightarrow \frac{\alpha_{s, 2} W_{s}}{F_{0}^{1}} \uparrow \& P_{0}, \mathbb{E}_{0}\left[P_{1}\right], F_{0}^{1} \uparrow \quad \mathrm{I}
$$


Table 2: Effect of Greater Financialization on the Long Futures Position and Oil Price Levels

\begin{tabular}{|c|c|c|c|c|c|c|}
\hline $\begin{array}{c}\text { Shift in } \downarrow \text { Effect on } \rightarrow \\
\text { Baseline value } \rightarrow\end{array}$ & $\begin{array}{c}\frac{\alpha_{s, 1} W_{s, 0}}{F} \\
0.86\left(86 \% \text { of } Q_{0}\right)\end{array}$ & $\begin{array}{l}\text { Hypothesis } \\
\text { prediction }\end{array}$ & $\begin{array}{c}P_{0} \\
\text { Baseline value }\end{array}$ & $\begin{array}{c}\mathbb{E}_{0}\left[P_{1}\right] \\
1.01 \text { of } P_{0}\end{array}$ & $\begin{array}{c}F_{0}^{1} \\
0.9 \text { of } P_{0}\end{array}$ & $\begin{array}{l}\text { Hypothesis } \\
\text { prediction }\end{array}$ \\
\hline Greater Financialization & & $\%$ diff & from baseline & & & \\
\hline $\begin{array}{c}\text { Financial speculators' risk aversion } \\
\tau_{s}: 2 \text { to } 1.5\end{array}$ & 2.4 & $+\mathrm{ve}$ & 0.8 & -0.8 & 0.7 & $+\mathrm{ve}$ \\
\hline $\begin{array}{c}\text { Financial speculators' wealth } \\
W_{s, 0}: 25 \% \text { increase }\end{array}$ & 2.0 & $+\mathrm{ve}$ & 0.6 & -0.6 & 0.6 & $+\mathrm{ve}$ \\
\hline Other Financial Layer Changes & & $\%$ diff & from baseline & & & \\
\hline $\begin{array}{c}\text { Risk-free rate } \\
r_{f}: 3.5 \% \text { to } 2.0 \%\end{array}$ & 4.3 & & 1.5 & -1.5 & -0.6 & \\
\hline Physical Layer Changes & & $\%$ diff & from baseline & & & \\
\hline $\begin{array}{c}\text { Supply news } \\
\mu_{g, 1}: 5 \% \text { loosening }\end{array}$ & -14.0 & & -10.5 & -2.9 & -1.9 & \\
\hline $\begin{array}{l}\text { Supply volatility } \\
\sigma_{g}: 8.0 \mathrm{pp} \text { to } 9.3 \mathrm{pp}\end{array}$ & -0.5 & & -0.5 & 1.8 & -1.1 & \\
\hline
\end{tabular}

Table 2 puts this to the test. In the first row, we see the effect of a lower risk aversion on the amount of money dedicated by financial speculators to oil contracts, the current spot price, its expected level, and the futures price. Lowering financial players' risk aversion from 2 to 1.5 does indeed raise their stake (by 2.4 per cent). A 25 per cent rise in assets at their disposal also raises their oil futures' investment by a similar proportion. These effects seem quite small compared to secular trends, shifts, and volatilities in actual financial participations.

The third row explores the lower risk-free rate. A lower risk-free rate raises the relative size of oil futures to the portfolio as well as stimulating risky equity holdings. This is line with a typical qualitative description of the search for yield effect. But the quantitative effect of the lower real rate on exposure to oil is quite small (at 4.3 per cent), when judged against the large sustained fall in real rates that creates it.

The last two rows describe the effect of changes to the physical layer: a more abundant expected future supply and a rise in the uncertainty surrounding that expectation. These changes are shown to have the potential to create large shifts in financial players' long positions. This is simply because the counterpart to the financial players' speculations are the physical investors' hedging needs. When the risk and return to physical oil changes, the demand for hedging will shift to alter the positions of financial speculators. In our model, a 5 per cent expected loosening in supply implies a potential loss for physical speculators and diminishes their appetite to hedge by nearly 14 per cent. While the small rise in supply uncertainty should raise the demand for hedging, it also raises the risk to financial speculators of providing that service. In net, it implies a 0.5 per cent fall in financial players' investments.

In terms of price levels, the prediction of the hypothesis is that these should rise following 
financialization. Although the current spot price does rise by about half a percent point in response to lower risk aversion or increased wealth, the expected spot price falls by the same extent. As we explained in Section 2.6, this is a general characteristic of any change in the financial layer: if the expected price and the spot price move, they must move in opposite directions. To the extent that the financialization hypothesis predicts a shift up in the term structure, this is clearly rejected.

The effect of lower risk-free rates on expected appreciation and the inverted basis is larger than the 1.5pp fall in rates. As we discussed in Section 2.6, because of the convenience yield, a fall in the next period price level lowers the risk of disruptive shortage. Hence in contradiction to Hotelling's simple rule and perhaps also the intuition of (Keynes, 1931, 100), a sustained large fall in risk-free rates can have some important effects on oil spreads.

Physical layer changes also have much larger effects on the oil price than do financial layer changes. The 5 per cent expected increase in net supply has a powerful effect on the spot price level, lowering it by just over 10 per cent. As less inventory is carried over, there is also a fall in the expected spot price level of nearly 3 per cent and the futures price by 2 per cent. And even the modest rise in net supply volatility raises the expected spot price by much more than does a 25 per cent increase in financial speculators' wealth. The current price falls as the expected price rises, although the rise in the expected price is, in this case, much larger. This is consistent with there being a rise in compensation to physical investors for the extra risk.

Where does this leave the empirical literature on financialization that links the large rise in net positions of non-commercial players to the oil price? We have shown that financialization shifts are unlikely to explain the large shifts in the oil price level. Instead these can more plausibly be due to expectational shifts in the demand and supply for spot oil. The net positions of non-commercial players need not only be due to shifts in financial players' preferences and constraints, financial investment volumes themselves depend on expected changes in the physical layer. Thus a correlation between a greater volume of financial flows and higher oil prices is not conclusive evidence of the financialization hypothesis.

\subsection{The Effect of Financialization on Inventory Sensitivity and Price Discov- ery}

The next sub-hypothesis is that inventory has become less effective in its role of smoothing price differentials because of financialization. French (1986) formalized the argument in a model with a 
posited function for holding inventory. He showed that if the marginal costs of holding inventory are large, then futures prices are very insensitive to shifts in the current period, as there is little response of carry over. In the extreme, prices become dislocated across time - analogously to the intertemporal prices of goods which spoil quickly. The relationship between inventory cost and price differentials is tested empirically across commodities by Fama and French (1987).

The sub-hypothesis that financialization has dislocated oil markets intertemporally is formalized as:

Greater financialization $\Rightarrow Q_{0} \downarrow \&\left|\frac{\mathbb{E}_{0}\left[P_{1}\right]}{P_{0}}-1\right| \uparrow \&\left|\frac{P_{0}}{F_{0}^{1}}-1 \uparrow\right| \&\left|\frac{\mathbb{E}_{0}\left[P_{1}\right]}{F_{0}^{1}}-1\right| \uparrow$

where $\left.X\right|_{p, 1}$ is the effect of a shock in the physical layer which is expected to occur in period 1 on the elasticity $X$.

Table 3: Effect of Greater Financialization on Total Carry Over and Spreads

\begin{tabular}{|c|c|c|c|c|c|c|}
\hline $\begin{array}{c}\text { Shift in } \downarrow \text { Effect on } \rightarrow \\
\text { Baseline value } \rightarrow\end{array}$ & $\begin{array}{c}Q_{0} \\
1.00\end{array}$ & $\begin{array}{l}\text { Hypothesis } \\
\text { prediction }\end{array}$ & $\begin{array}{l}\frac{\mathbb{E}_{0}\left[P_{1}\right]}{P_{0}} \\
1.01\end{array}$ & $\begin{array}{c}\frac{P_{0}}{F_{0}^{1}} \\
1.12\end{array}$ & $\begin{array}{l}\frac{\mathbb{E}_{0}\left[P_{1}\right]}{F_{0}^{1}} \\
1.13\end{array}$ & $\begin{array}{l}\text { Hypothesis } \\
\text { prediction }\end{array}$ \\
\hline Greater Financialization & \multicolumn{6}{|c|}{$\%$ diff. from baseline } \\
\hline $\begin{array}{c}\text { Financial speculators' risk aversion } \\
\tau_{s}: 2 \text { to } 1.5\end{array}$ & 0.2 & -ve & -1.5 & 0.1 & -1.4 & $+\mathrm{ve}$ \\
\hline $\begin{array}{c}\text { Financial speculators' wealth } \\
W_{s, 0}: 25 \% \text { increase }\end{array}$ & 0.2 & -ve & -1.3 & 0.1 & -1.2 & $+\mathrm{ve}$ \\
\hline Other Financial Layer Changes & \multicolumn{6}{|c|}{$\%$ diff. from baseline } \\
\hline $\begin{array}{c}\text { Risk-free rate } \\
r_{f}: 3.5 \% \text { to } 2 \% \\
\end{array}$ & \multicolumn{2}{|l|}{0.5} & -3.0 & 2.2 & -0.9 & \\
\hline Physical Layer Changes & \multicolumn{6}{|c|}{$\%$ diff. from baseline } \\
\hline $\begin{array}{c}\text { Supply news } \\
\mu_{g, 1}: 5 \% \text { restriction }\end{array}$ & \multicolumn{2}{|l|}{-3.5} & 8.5 & -8.8 & -1.0 & \\
\hline $\begin{array}{l}\text { Supply volatility } \\
\sigma_{g}: 8.0 \mathrm{pp} \text { to } 9.3 \mathrm{pp}\end{array}$ & \multicolumn{2}{|l|}{-0.1} & 2.3 & 0.7 & 3.0 & \\
\hline
\end{tabular}

Looking across the first two rows of Table 3 , greater financialization - whether due to lower risk aversion or more wealth - is predicted to raise the amount of carry over, contradicting the financialization hypothesis 13 As for spreads, while the basis is increased by the financialization shifts, this is to a tiny degree. Other spreads, in particular the risk premium, narrow. This is simply because a greater propensity to bear risk by financial speculators and an expansion of the resources at their disposal enhances their ability to bear risk. In a similar fashion, a lower risk-free rate lowers the opportunity costs of betting on financial futures.

In Section 2.6, we predicted that a shift in the financial layer could only lead to a large rise in current spot price levels if it also implies a large differential reaction between the risk premium and the basis, such that the gap between the two becomes more negative. According to Table

\footnotetext{
${ }^{13}$ This is in line with Acharya, Lochstoer, and Ramadorai (2011)'s qualitative findings.
} 
3, the gap does become more negative because of the two financialization shifts but only by just over 1pp. The rough calculations in Section 2.6 imply that this would be consistent with a small rise in the current price level (of about half a percent) in either case. And indeed, this is very close to the reactions reported in Table 2

In contrast, news of more net supply in the future lowers carry over to a significant extent - a 5 per cent expected increase in supply lowers carry over by 3.5 per cent. Crucially, only the expected loosening comes close to reproducing the effects on the basis estimated in Table 1 to have taken place. With a 5 per cent loosening in expected net supply, the basis falls by 8.8pp, as there is a lower convenience yield. This is perfectly consistent with the idea that the excess supply was eliminated from mid-2008 and is quite close to the estimate of a $6.5 \mathrm{pp}$ fall. The loosening in expected net supply can also generate a small fall in the risk premium and a large rise in expected appreciation. These are qualitatively consistent with what we would expect, although matching the timing and size of shifts is more difficult than with the basis, as these spreads are unobservable. The last row shows that any accompanying extra supply uncertainty would have raised the risk in holding inventory, and thus raised all spreads, and acted to lower the quantity carried over further.

Thus if the evidence is that the basis and financial participation both fell in mid-2008, it seems more plausible that the realization of a glut could have been responsible rather than any change in financialization. Anticipations of physical layer developments are also uniquely capable of explaining the subsequent recovery in the basis (Chart 2).

It is perhaps more surprising that the effects of financialization are small in size. This intuition follows from the interpretation of the model in terms of the demand and supply for storage services in Section 2.5 .

Note first that the price elasticities of the demand and supply of storage services ( 19 and 20 respectively) are not independent: the crucial parameter in both is $\eta \equiv \frac{1-\varsigma}{\theta+\omega \varsigma}$, the inverse of the demand and supply elasticities. This is because the supply of storage is chosen as a nominal value - a financial asset - by physical speculators and therefore the spot price elasticities affect the implied real volume of carry over. Thus, the high baseline value of $\eta$ (3.14) implies that the supply of, as well as the demand for, storage is relatively insensitive to price.

Financialization changes affect the supply of storage and thus the amount of carry over (equation 20) with the same elasticity as does expected appreciation. Thus the notoriously low supply and demand elasticities for oil must be one part of the reason why financialization has 
weak effects on inventory. But another crucial mechanism must be that financialization (here summarized in $\kappa$ ) does not drive large wedges in the risk premium (Table 5). This is because physical speculators can absorb the effect of these changes through shifting the mix of hedged and unhedged inventory, and financial speculators can accept some of the risk to the extent they can diversify through other investments, as discussed in Section 2.6.

The first column of Table 2 reports the futures positions of financial speculators. As this is very nearly the same as the hedged component of carry over, we see larger proportionate effects on the hedged carry over than on total carry over, indicating that greater financialization raises the hedge ratio. For example when financial speculators' wealth increases by a quarter, the amount of hedged inventory increases by 2.5 per cent, such that the hedge ratio rises by $1 \mathrm{pp}$.

A greater amount of carry over elicited could be seen as an improvement in price discovery if there is, for example, a greater reaction of current spot prices to future information. On the other hand, if financialization interferes with market efficiency, near prices should be relatively less sensitive to distant shocks than they were before. This resonates with Kaldor (1939)'s argument that speculation is destabilizing when inventory fails to perform its role of buffering against changes in future prospects and when current prices fail to perform their role of signalling on those prospects. Formally,

$$
\text { Greater financialization } \Rightarrow\left|\frac{\partial \ln P_{0}}{\partial \mu_{g, 1}}\right| \downarrow
$$

where $\frac{\partial \ln X}{\mu_{g, 1}}$ is the proportionate response of the price $X$ to an expected increase in net supply. The oil market spreads in an artificial equilibrium where there is no uncertainty are

$$
\frac{\bar{P}_{1}}{\bar{P}_{0}}=\frac{\left(1+r_{f}\right)}{e^{\bar{c}_{q, 1}}}, \frac{\bar{P}_{0}}{\bar{F}_{0}^{1}}=\frac{e^{\bar{c}_{q, 1}}}{\left(1+r_{f}\right) e^{\mu_{r e, 1}-\mu_{c g}}} \text { and } \frac{\bar{P}_{1}}{\bar{F}_{0}^{1}}=\frac{1}{e^{\mu_{r e, 1}-\mu_{c g}}}
$$

Thus, only in the absence of uncertainty, would spreads between the prices be completely independent of the parameters determining expected net supply and also financialization (risk aversion of financial players' wealth). Only then would spreads reflect purely the differences in the physical cost of carry, the opportunity cost of tied up funds, and margin fees, while the three price levels would depend in exactly the same way on taste, demand, and supply factors, as well as risk aversion or financial wealth 14

\footnotetext{
${ }^{14}$ Indeed this was the main argument of Working's classic paper, Working (1949): the timing of the shock is quite unrelated to the reactions of prices differentiated by the timings of their transactions, implying also that future prices are not expected to be significantly better predictors of future shocks than spot prices themselves.
} 
Once we allow for uncertainty, and also a convenience yield, there will be a reaction in spreads to shocks. To show this, we present numerical reaction of spreads to news on future supply shocks. Formally $\mu_{g, 1}$ is lowered in equation 17 to raise prices. As this is a news shocks, there is uncertainty surrounding this new estimate of supply, and that uncertainty is incorporated into decisions as the model is not one of certainty equivalence. (We do not need to consider current demand shocks as they have identical effects to supply shocks, justifying the typical assumption of a net supply shock in the theoretical literature.)

We simulated for a vector of equally spaced negative and positive news about supply within a range around the baseline value. The results shown in Table 4 are the average of the numerical derivatives across these points, with each entry capturing the proportional movements of key price variables relative to that of the supply level. For example where there is an expectation of a 1 per cent higher supply, the top rightmost entry of the table explains that spot prices will fall by 2 per cent of their baseline value.

Table 4: Relative Price Responses to Supply Shocks (baseline)

\begin{tabular}{ccc}
\hline Variable & Formula & $\begin{array}{c}\text { Shock to } \\
\text { Supply } \\
\text { News }\end{array}$ \\
\hline Current Spot Price & $\frac{\partial \ln P_{0}}{\partial \mu_{g, 1}}$ & -2.09 \\
Expected Spot Price & $\frac{\partial \ln \mathbb{E}_{0}\left[P_{1}\right]}{\partial \mu_{g}, 1}$ & -0.71 \\
Futures Price & $\frac{\partial \ln F_{0}^{1}}{\partial \mu_{g}, 1}$ & -0.51
\end{tabular}

Table 4 confirms that under uncertainty and with a convenience yield, spreads may react very differently to anticipated net supply developments, and proportionate reactions are not one for one. Current prices are the most sensitive to future developments in supply: a 1 per cent greater supply will lower spot prices by 2 per cent. Futures prices react much less than either expected or current spot prices. This makes the basis in particular very sensitive to the future supply shock.

Having set the scene, Table 5 below describes the effect of financialization on the sensitivity of these spreads.

See also the recent survey by Alquist, Kilian, and Vigfusson (2011). 
Table 5: Effect of Greater Financialization on Oil Price Sensitivity to Supply Shock News

\begin{tabular}{|c|c|c|c|c|}
\hline Shift in $\downarrow$ & & Effect on - & & \\
\hline Baseline value $\rightarrow$ & $\begin{array}{l}\frac{\partial \ln P_{0}}{\partial \mu_{g, 1}} \\
-2.09\end{array}$ & $\begin{array}{l}\text { Hypothesis } \\
\text { prediction }\end{array}$ & $\begin{array}{c}\frac{\partial \ln \mathbb{E}_{0}\left[P_{1}\right]}{\partial \mu_{g, 1}} \\
-0.71\end{array}$ & $\begin{array}{l}\frac{\partial \ln F_{0}^{1}}{\partial \mu_{g, 1}} \\
-0.51\end{array}$ \\
\hline Greater Financialization & \multicolumn{4}{|c|}{ Diff. from baseline } \\
\hline $\begin{array}{c}\text { Financial speculators' risk aversion } \\
\tau_{s}: 2 \text { to } 1.5\end{array}$ & -0.01 & $+\mathrm{ve}$ & 0.01 & -0.03 \\
\hline $\begin{array}{c}\text { Financial speculators' wealth } \\
\qquad W_{s}: 25 \% \text { increase }\end{array}$ & -0.01 & $+\mathrm{ve}$ & 0.01 & -0.01 \\
\hline Other Financial Layer Changes & \multicolumn{4}{|c|}{ Diff. from baseline } \\
\hline $\begin{array}{l}\text { Risk-free rate } \\
r_{f}: 3.5 \% \text { to } 2 \%\end{array}$ & 0.03 & & -0.03 & -0.03 \\
\hline Physical Layer Changes & \multicolumn{4}{|c|}{ Diff. from baseline } \\
\hline $\begin{array}{c}\text { Supply news } \\
\mu_{g, 1}: 5 \% \text { restriction }\end{array}$ & -0.28 & & 0.28 & 0.29 \\
\hline $\begin{array}{c}\text { Supply volatility } \\
\sigma_{g}: 8.0 p p \text { to } 9.3 \mathrm{pp}\end{array}$ & 0.04 & & -0.04 & 0.04 \\
\hline
\end{tabular}

Considering equation 15, we can see that the cross-responses of current and expected spot prices to an expected supply shock and any other structural change acting through inventory cross-responsiveness will be equal absolute magnitude but of opposite sign: $\left(\frac{\partial^{2} \ln P_{0}}{\partial \mu_{g, 1} \partial x}=\right.$ $-\frac{\partial^{2} \ln Q_{0}}{\partial \mu_{g, 1} \partial x}=-\frac{\partial^{2} \ln \mathbb{E}_{0}\left[P_{1}\right]}{\partial \mu_{g, 1} \partial x}$ for a structural shift in $\left.x\right)$. The implication is that if the sensitivity of current spot prices is lowered as a consequence the structural change, then the sensitivity of expected spot prices must rise (and vice versa). This is indeed what we observe in the first two columns of Table 5 .

Greater financialization, as represented by a lower risk aversion or more resources for financial speculators, makes near prices more responsive to distant shocks and future prices less responsive ${ }^{15}$ Interestingly, though lower real interest rates raise the amount of carry over (Table 3), they lower its sensitivity to supply shocks.

As we can see in the lowest row, a looser supply improves the responsiveness of the current price relative to the distance price. Conversely, a tighter supply can significantly attenuate the responsiveness of the current price relative to the distant price. In essence this is because tighter supply induces greater uncertainty in arithmetic returns - a scaling effect. The greater volatility worsens the market signal on future fundamentals and blocks the passage of future information onto the current price.

According to these results, then, there is no support for the view that greater financialization interferes with the ability of inventory to absorb shocks. Quite the contrary. And here again

\footnotetext{
${ }^{15}$ This is consistent with Samuelson $\sqrt{1965)}$ who argued that spot prices should be less sensitive to supply shocks than future shocks when there are high levels of inventory, in comparison to the position levels are low. As the levels of inventory are slightly improved by greater financialization, we should expect there to be little differential response in the relative reactions of current and future prices. Though his results depend on what changes are taking place, they seem to apply for our two financialization experiments.
} 
there is an alternative explanation: looser supply can explain a fall in carry over, a lower basis, a lower risk premium, and a greater expected appreciation. The results of this section are also consistent with the responsiveness of spreads to information being little affected by financialization. If anything, price discovery should be improved by financialization.

\subsection{Effect of Financialization on the Reaction of Prices to Financial Shocks}

The third sub-hypothesis is that current spot prices have become more sensitive to shocks arising in the financial layer of oil markets, for example in predicted stock market returns. To explore this, we simulate for shifts in news about risky share returns; a different log return on shares is expected but with uncertainty surrounding this prospect. Formally we vary $\mu_{r e, 1}$ in equation 17. As with the supply shock, we simulate for a vector of equally spaced negative and positive deviations within a range around the baseline value and take an average of the differences between these points. The first shock was to the physical layer of the oil market. This is to the financial layer. Formally

$$
\text { Greater financialization } \Rightarrow \frac{\partial \ln P_{0}}{\partial \mu_{r e, 1}} \uparrow \& \frac{\partial \ln \mathbb{E}_{0}\left[P_{1}\right]}{\partial \mu_{r e, 1}} \uparrow \& \frac{\partial \ln F_{0}^{1}}{\partial \mu_{r e, 1}} \uparrow \quad \text { IV }
$$

where $\left.\frac{\partial \ln X}{\mu_{r e, 1}}\right|_{f, 1}$ is the effect of a shock to expected share returns on $X$ in log percentage terms. Table 6 reports the baseline values of this sensitivity.

Table 6: Baseline Values of Oil Price Sensitivity to Share Return News

\begin{tabular}{cccc}
\hline Effect on $\rightarrow$ & $\frac{\partial \ln P_{0}}{\partial \mu_{r e, 1}}$ & $\frac{\partial \ln \mathbb{E}_{0}\left[P_{1}\right]}{\partial \mu_{r e, 1}}$ & $\frac{\partial \ln F_{0}^{1}}{\partial \mu_{r e, 1}}$ \\
Baseline value $\rightarrow$ & 0.34 & -0.34 & -0.66
\end{tabular}

We see that in the baseline, an anticipated rise in the mean log share return would raise the current spot price and lower the expected spot price to the same extent, in keeping with the intuition of Section 2.6. The futures prices would also fall. Thus expected appreciation is most affected by anticipations of share returns, the basis is hardly affected, and the risk premium is somewhat lower. A 1 pp increase in share returns raises the spot price by 0.34 per cent meaning it would take a rise in mean share returns of an large size $\left(3\left(\approx \frac{1}{0.34}\right)\right.$ pps $)$ to generate even a 1 per cent fall in oil spot prices.

Table 7 reports how financialization shifts these sensitivities from this baseline. 
Table 7: Effect of Greater Financialization on Oil Price Sensitivity to Share Return News

\begin{tabular}{|c|c|c|c|c|}
\hline $\begin{array}{c}\text { Shift in } \downarrow \text { Effect on } \rightarrow \\
\text { Baseline value } \rightarrow\end{array}$ & $\begin{array}{c}\frac{\partial \ln P_{0}}{\partial \mu_{r, 1}} \\
0.34\end{array}$ & $\begin{array}{c}\frac{\partial \ln \mathbb{E}_{0}\left[P_{1}\right]}{\partial \mu_{r e, 1}} \\
-0.34\end{array}$ & $\begin{array}{l}\frac{\partial \ln F_{0}^{\perp}}{\partial \mu_{r e, 1}} \\
-0.66\end{array}$ & $\begin{array}{l}\text { Hypothesis } \\
\text { prediction }\end{array}$ \\
\hline Greater Financialization & \multicolumn{3}{|c|}{ Diff. from baseline } & \\
\hline $\begin{array}{c}\text { Financial speculators' risk aversion } \\
\tau_{s}: 2 \text { to } 1.5\end{array}$ & 0.06 & -0.06 & 0.01 & large differences \\
\hline $\begin{array}{l}\text { Financial speculators' wealth } \\
\qquad W_{s}: 25 \% \text { increase }\end{array}$ & 0.04 & -0.04 & 0.01 & large differences \\
\hline Other Financial Layer Changes & \multicolumn{3}{|c|}{ Diff. from baseline } & \\
\hline $\begin{array}{l}\text { Risk-free rate } \\
r_{f}: 3.5 \% \text { to } 2 \%\end{array}$ & -0.03 & 0.03 & -0.05 & \\
\hline Physical Layer Changes & \multicolumn{3}{|c|}{ Diff. from baseline } & \\
\hline $\begin{array}{c}\text { Supply News } \\
\mu_{g, 1}: 5 \% \text { restriction }\end{array}$ & 0.05 & -0.05 & -0.03 & \\
\hline $\begin{array}{l}\text { Supply volatility } \\
\sigma_{g}: 8.0 \mathrm{pp} \text { to } 9.3 \mathrm{pp}\end{array}$ & -0.04 & 0.04 & -0.02 & \\
\hline
\end{tabular}

The first two rows describe how spot price sensitivities to mean equity returns are increased by lower risk aversion and greater wealth of financial players. The current and expected spot price become slightly more responsive to expected share returns than in the baseline. Nevertheless this effect is quantitatively not large and the sensitivity remains very low. All other effects are negligible. The stark message is that oil price spreads do not become more sensitive to news about share returns just because of shifts in financial players' preferences and resources.

For completeness, we can note that the conditional correlation between equity returns and the risk premium in log and arithmetic form are :

$$
\begin{aligned}
& \operatorname{Corr}_{0}\left[p_{1}-f_{0}^{1}, r_{e, 1}\right]=\frac{\sigma_{\text {pre }}}{\sigma_{r} \operatorname{Var}_{0}\left[P_{1}\right]^{0.5}} ; \\
& \operatorname{Corr}_{0}\left[\frac{P_{1}}{F_{0}^{1}}-1, R_{e, 1}-1\right]=\frac{\left(e^{\sigma_{p r e}}-1\right)}{\left(\left(e^{\sigma_{r}^{2}}-1\right)\left(e^{\operatorname{Var}_{0}\left[P_{1}\right]}-1\right)\right)^{0.5}}
\end{aligned}
$$

where $\sigma_{\text {pre }} \equiv \frac{\varsigma \sigma_{y r e}}{\theta+\omega \varsigma}$. Several empirical studies have discussed the impact of greater financialization on these dynamic correlations (Silvennoinen and Thorp (2010) and Tang and Xiong (2010) for example). But according to equation 27, these correlations are completely independent of the risk aversion or wealth of financial speculators and different correlations can only be the outcome of physical layer changes 16

\footnotetext{
${ }^{16}$ It might matter in this regard that in a two-period model, inventory decisions are simply a question of transferring stock from the current period to the future and there is no uncertainty surrounding the amount of carry over.
} 


\subsection{Effect of Financialization on Unpredictability}

The fourth sub-hypothesis is that financialization has increased the unpredictability of spot oil prices to make the futures price a worse predictor of next-period spot prices:

$$
\text { Greater financialization } \Rightarrow\left(\operatorname{Var}_{0}\left[P_{1}\right]\right)^{0.5} \uparrow \quad \mathrm{V}
$$

The effect of financialization on the conditional standard deviation of oil prices is explored in Table 8 below.

Table 8: Effect of Greater Financialization on Oil Price Unpredictability

\begin{tabular}{ccc}
\hline $\begin{array}{c}\text { Shift in } \downarrow \text { Effect on } \rightarrow \\
\text { Baseline value } \rightarrow\end{array}$ & $\left(\operatorname{Var}_{0}\left[P_{1}\right]\right)^{0.5}$ & $\begin{array}{c}\text { Hypothesis } \\
\text { prediction }\end{array}$ \\
\hline Greater Financialization & $\%$ diff. from baseline & \\
\hline Financial speculators' risk aversion & -0.8 & + ve \\
$\tau_{s}: 2$ to 1.5 & -0.6 & + ve \\
Financial speculators' wealth & & + ve \\
$W_{s}: 25 \%$ increase & $\%$ diff. from baseline & \\
\hline Other Financial Layer Changes & -1.5 & \\
\hline Risk-free rate & & \\
$r_{f}: 3.5 \%$ to $2 \%$ & diff. from baseline & \\
\hline Physical Layer Changes & -2.9 & \\
Supply news & & \\
$\mu_{g, 1}: 5 \%$ restriction & & \\
Supply volatility & &
\end{tabular}

The size of the effect of these changes on the unpredictability of the price level are equal to the proportional reaction of the mean of the price level (see the penultimate column of Table 2). This follows from the properties of a log-normally distributed variable when only the mean of its log is changed: as the scale of the price level is changed, so is its variance. The glaring exception is when there is higher supply volatility, which increases the volatility of the price level by nearly 17 per cent independently of scale.

It then follows that greater financialization should lower the standard deviation and improve the precision of the price signal. For example a lower risk aversion of financial speculators would improve the ability of the market to absorb risk. Thus, here also, the financialization hypothesis is contradicted. But even then the effects of financialization are less than those of physical layer changes. A higher supply volatility raises unpredictability by 19 per cent. This is an impact of a much greater magnitude than the changes in financialization. It would seem more plausible to attribute changes in the predictability of spot prices to shifts in fundamental volatility. 


\section{Welfare}

In this final section we look at the implications of financialization for welfare. A necessary step is to extend the model to take account of consumers' utility as that will be the basis of our welfare calculations.

\subsection{Extending the Model for Consumer Welfare}

Consumer welfare is calculated by taking a second-order approximation to consumers' lifetime utility (equation (9)) about the deterministic steady-state for period 1 log consumption, and then taking expectations at time 0 :

$$
\begin{aligned}
& \mathbb{E}_{0} \Pi_{c, 0}=U\left(C_{c, 0}\right)+\beta \mathbb{E}_{0} U\left(C_{c, 1}\right) \\
& \approx U\left(\bar{C}_{c, 0}\right)+\beta U\left(\bar{C}_{c, 1}\right)+\beta \bar{C}_{c, 1} U_{1}\left(\bar{C}_{c, 1}\right)\left(\mathbb{E}_{0}\left[c_{c, 1}\right]-\ln \bar{C}_{c, 1}\right) \\
& +\frac{\beta}{2}\left(\bar{C}_{c, 1} U_{1}\left(\bar{C}_{c, 1}\right)+\left(\bar{C}_{c, 1}\right)^{2} U_{2}\left(\bar{C}_{c, 1}\right)\right)\left(\operatorname{Var}_{0}\left[c_{c, 1}\right]+\left(\mathbb{E}_{0}\left[c_{c, 1}\right]-\ln \bar{C}_{c, 1}\right)^{2}\right) .
\end{aligned}
$$

In order to calculate welfare, we need to solve for the steady-state values of consumption, $\left(\bar{C}_{c, s}\right.$ for $\left.\mathrm{s}=[0,1]\right)$, the conditional mean of the log of second-period consumption, $\left(\mathbb{E}_{0}\left[c_{c, 1}\right]\right)$, and its conditional variance, $\left(\operatorname{Var}_{0}\left[c_{c, 1}\right]\right)$. In Appendix C, we describe how these latter two values can be approximated up to second order.

Welfare is assessed in terms of the known percentage of consumption in all dates that is required to compensate consumers for the structural change so that their utility is as in the baseline. As $\Pi_{\text {base }}^{c}+\frac{(1+\beta)}{1-\chi}=\left(\Pi^{c}+\frac{(1+\beta)}{1-\chi}\right)\left(1+C_{w}\right)^{1-\chi} \Rightarrow C_{w}=100 \times\left(\left(\frac{\Pi_{\text {base }}^{c}+\frac{(1+\beta)}{1-\chi}}{\Pi^{c}+\frac{(1+\beta)}{1-\chi}}\right)^{\frac{1}{1-\chi}}-1\right)$.

The suggestion that financialization worsens the welfare of final consumers is put to the test formally as:

$$
\text { Greater financialization } \Rightarrow C_{w} \uparrow \quad \text { VI }
$$


Table 9: Effect of Greater Financialization on Consumer Welfare

\begin{tabular}{ccc}
\hline Shift in $\downarrow$ Effect on $\rightarrow$ & $C_{w}$ & \\
& Compensation relative & Financialization hypothesis \\
\hline Financialization changes & Diff. from baseline & + ve \\
\hline Financial speculators' risk aversion & -0.02 & + ve \\
Financial speculators' wealth & & \\
$W_{s}: 25 \%$ increase & -0.01 & + ve \\
\hline Other Financial Layer Changes & Diff. from baseline & \\
\hline Risk-free rate & -0.03 & \\
$r_{f}: 3.5 \%$ to $2 \%$ & Diff. from baseline & \\
\hline Physical Layer Changes & -0.06 \\
Supply news & 0.02 \\
$\mu_{g, 1}: 5 \%$ loosening & \\
Supply volatility & &
\end{tabular}

A more positive value in the table (of $C_{w}$ ) implies that welfare is lower than the baseline and positive compensation is required. The simulations reveal that greater financialization arising from either lower risk aversion, more speculator wealth, or a lower risk-free rate will improve welfare (by reducing the welfare compensation). This is due to the benefits of risk-sharing, and is consistent with our previous results. The forecasted 5 per cent loosening in net supply which lowers the expected spot price by 10 per cent has the most powerful effect on improving consumers' welfare in this example, equivalent to 0.06 pp less consumption compensation. Even the mild rise in supply volatility worsens welfare by $0.02 \mathrm{pp}$, which is due to the higher price level under greater uncertainty ${ }^{17}$

Finally, we explore the sensitivity of consumer welfare to shocks, assessing whether or not this is worsened by financialization:

$$
\text { Greater financialization }\left.\Rightarrow \frac{\partial C_{w}}{\partial P_{0}} P_{0}\right|_{p, 1} \uparrow
$$

\footnotetext{
${ }^{17}$ The intuition behind these welfare effects is simply that tighter supply conditions raise the expected level of oil prices and lower the mean of log consumption. Lucas (2003)'s famous calculation of a small effect of uncertainty was based on a model where consumption was log-linear. Here consumption is not conditionally loglinear, and greater uncertainty can affect the expected value of its log.
} 
Table 10: Effect of Greater Financialization on Consumer Welfare Cost Sensitivity to Supply News

\begin{tabular}{ccc}
\hline $\begin{array}{c}\text { Shift in } \downarrow \text { Effect on } \rightarrow \\
\text { Baseline value } \rightarrow\end{array}$ & $\begin{array}{c}\left.\frac{\partial C_{w}}{\partial P_{0}} P_{0}\right|_{p, 1} \\
0.01\end{array}$ & $\begin{array}{c}\text { Financialization hypothesis } \\
\text { prediction }\end{array}$ \\
\hline Greater Financialization & Diff. from baseline & + ve \\
\hline Financial speculators' risk aversion & $-0.1 \times 10^{3}$ & + ve \\
$\tau_{s}: 2$ to 1.5 & $-0.2 \times 10^{3}$ & + ve \\
Financial speculators' wealth & & \\
$W_{s}: 25 \%$ increase & $0.4 \times 10^{3}$ & \\
\hline Other Financial Layer Changes & Diff. from baseline & \\
\hline Risk-free rate & & \\
$r_{f}: 3.5 \%$ to $2 \%$ & Diff. from baseline & \\
\hline Physical Layer Changes & $2.3 \times 10^{3}$ & \\
Supply news & & \\
$\mu_{g, 1}: 5 \%$ restriction & $0.5 \times 10^{3}$ & \\
Supply volatility & & \\
$\sigma_{g}: 8.0$ pp to $9.3 p p$ & &
\end{tabular}

The results are in Table 10 above. The baseline value of the semi-elasticity $\left.\frac{\partial C_{w}}{\partial P_{0}} P_{0}\right|_{p, 1}$ is 0.01 meaning that news of higher future supply that lowers current spot prices by $1 \%$ will lower the necessary consumption equivalent welfare compensation by $0.01 \mathrm{pp}$. This confirms that fundamental shocks do indeed matter in the model.

The rest of Table 10 describes what happens to this semi-elasticity following financialization and other changes. In the case of either a lower risk aversion or greater resources, financialization hardly affects the sensitivity of consumers' welfare. The loosening in supply of 5 per cent has the most important impact in raising consumers' exposure; consumers' welfare exposure to supply news will be increased by about $0.002 \mathrm{pp}$. These results reject any deleterious effect on consumer welfare sensitivity of financialization.

\section{Conclusion}

We find no support for the various strands of the financialization hypothesis. Financialization has little effect on oil market variables and final consumers' welfare. In part, this is because inventory managers can manipulate the margin between hedged and unhedged inventory to shield final consumers. But also there are general limits on the ability of financialization shocks to shift the expected spot price term structure. In contrast, anticipations of net supply shifts and net supply volatility have important impacts on spreads, welfare, and even on financial market participation. Those papers that purport to have found a significant impact of financialization without considering the reverse causality are vulnerable to poor identification.

In the spirit of instrumentalism, we have concentrated around a null hypothesis that fi- 
nancialization is a bad thing, but there are some who have argued that financialization brings benefits. In his recent book, (Pirrong, 2012, 68) has explained how the entry of new players with a higher degree of risk tolerance should promote diversification. We find that the effects are beneficial. However this question can be more comprehensively answered in a model which allows for intertemporal maximization by consumers and producers.

We have not allowed for all the frictions displayed in real world financial markets. For example, financial speculators in our paper are not leveraged, and maximize objectives that are broadly consistent with low systemic risk. It is also true that we disregard noise traders who experience an average loss. The presence of noise traders could very well explain destabilizing speculation (Kaldor (1939)) and could induce indeterminacy in oil prices. Nor do we allow for differences in information between participants, which then would, as in Danthine (1978) or Stein (1987), explain how oil prices transmit information to participants, reducing their risk. Then we also ignore the tack taken by Williams (1987). He argued that the cash or forward sale of oil requires uncertain transaction costs, because of matching. As these costs are uncertain, the outcome is similar to risk aversion in that future prices can be below spot prices, but the explanation lies in the matching process and how that is facilitated by a futures market.

If we were to depart from our assumptions along these directions then we might find a more significant effect of financialization. But even then, these fundamental market failures would elicit their own specific policy solutions. For example, if it were found that the entrance of highly leveraged financial speculators with socially suboptimal objectives disrupts oil markets, the implication is that macro and microprudential regulation should be employed. Thus, policies designed to correct for failures in other financial markets may not be appropriate for oil. Finally our paper shows that it is crucial in the first instance to identify the channels through which financialization can result in market failure. 


\section{A Appendix: Solving for Speculators' Portfolios}

The budget constraint of physical speculators (equation 1) can be written in log terms as:

$$
\begin{aligned}
& w_{r, 1}=w_{r, 0}+\ln \left(\left(1-\alpha_{r 1,0}-\alpha_{r 2,0}\right)\left(1+r_{f}\right)+\alpha_{r 1,0} \frac{P_{1} C_{q 1,1}}{P_{0}}+\alpha_{r 2,0} \frac{F_{0}^{1} C_{q 2,1}}{P_{0}}\right) \\
& \Rightarrow w_{r, 1} \approx w_{r, 0}+r_{r p, 1}
\end{aligned}
$$

where:

$$
r_{r p, 1} \equiv r_{f}+\ln \left(1+\alpha_{r 1,0}\left(e^{p_{1}-p_{0}+c_{q 1,1}-r_{f}}-1\right)+\alpha_{r 2,0}\left(e^{f_{0}^{1}-p_{0}+c_{q 2,1}-r_{f}}-1\right)\right)
$$

is the log portfolio return of the physical speculators. Consider a second-order approximation of $r_{r p, 1}$ with respect to $\mathbf{r}_{r s, 1}$ (as defined in the main text) about $r_{f} \boldsymbol{\iota}$ ):

$$
\begin{aligned}
& r_{r p, 1} \approx r_{f}+\left(\mathbf{r}_{r s, 1}-r_{f} \boldsymbol{\iota}\right) \boldsymbol{\alpha}_{r, 0}+\frac{1}{2} \operatorname{diag}\left(\left[\mathbb{E}_{0}\left[\mathbf{r}_{r s, 1}\right]-r_{f} \iota\right]\left[\mathbb{E}_{0}\left[\mathbf{r}_{r s, 1}\right]-r_{f} \boldsymbol{\iota}\right]^{T}\right) \boldsymbol{\alpha}_{r, 0} \\
& -\frac{1}{2} \boldsymbol{\alpha}_{r, 0}^{T}\left[\mathbb{E}_{0}\left[\mathbf{r}_{r s, 1}\right]-r_{f} \iota\right]\left[\mathbb{E}_{0}\left[\mathbf{r}_{r s, 1}\right]-r_{f} \iota\right]^{T} \boldsymbol{\alpha}_{r, 0}
\end{aligned}
$$

Taking expectations conditional on period 0 information:

$$
\begin{aligned}
& \mathbb{E}_{0}\left[r_{r p, 1}\right] \approx r_{f}+\left(\mathbb{E}_{0} \mathbf{r}_{r s, 1}-r_{f} \boldsymbol{\iota}\right) \boldsymbol{\alpha}_{r, 0} \\
& +\frac{1}{2} \operatorname{diag}\left(\operatorname{Var}_{0}\left[\mathbf{r}_{r s, 1}\right]\right) \boldsymbol{\alpha}_{r, 0}+\frac{1}{2} \operatorname{diag}\left(\left[\mathbb{E}_{0}\left[\mathbf{r}_{r s, 1}\right]-r_{f} \boldsymbol{\iota}\right]\left[\mathbb{E}_{0}\left[\mathbf{r}_{r s, 1}\right]-r_{f} \boldsymbol{\iota}\right]^{T}\right) \boldsymbol{\alpha}_{r, 0} \\
& -\frac{1}{2} \boldsymbol{\alpha}_{r, 0}^{T} \operatorname{Var}_{0}\left[\mathbf{r}_{r s, 1}\right] \boldsymbol{\alpha}_{r, 0}-\frac{1}{2} \boldsymbol{\alpha}_{r, 0}^{T}\left[\mathbb{E}_{0}\left[\mathbf{r}_{r s, 1}\right]-r_{f} \boldsymbol{\iota}\right]\left[\mathbb{E}_{0}\left[\mathbf{r}_{r s, 1}\right]-r_{f} \boldsymbol{\iota}\right]^{T} \boldsymbol{\alpha}_{r, 0}
\end{aligned}
$$

and

$$
\operatorname{Var}_{0}\left[r_{r p, 1}\right] \approx \boldsymbol{\alpha}_{r, 0}^{T} \operatorname{Var}_{0}\left[\mathbf{r}_{r s, 1}\right] \boldsymbol{\alpha}_{r, 0}
$$

Hence, $W_{r, 1}^{1-\tau_{r}}$ is conditionally log-normal such that:

$$
\ln \mathbb{E}_{0} W_{r, 1}^{1-\tau_{r}}=\left(1-\tau_{r}\right) w_{r, 0}+\left(1-\tau_{r}\right) \mathbb{E}_{0}\left[r_{r p, 1}\right]+\frac{1}{2}\left(1-\tau_{r}\right)^{2} \operatorname{Var}_{0}\left[r_{r p, 1}\right]
$$


Thus maximizing 1 is equivalent to maximizing the following expression:

$$
\begin{aligned}
& \frac{\ln \mathbb{E}_{0} W_{r, 1}^{1-\tau_{r}}-\left(1-\tau_{r}\right) w_{r, 0}}{1-\tau_{r}} \\
& =r_{f}+\left(\mathbb{E}_{0} \mathbf{r}_{r s, 1}-r_{f} \iota\right) \boldsymbol{\alpha}_{r, 0}+\frac{1}{2} \operatorname{diag}\left(\operatorname{Var}_{0}\left[\mathbf{r}_{r s, 1}\right]\right) \boldsymbol{\alpha}_{r, 0}+\frac{1}{2} \operatorname{diag}\left(\left[\mathbb{E}_{0}\left[\mathbf{r}_{r s, 1}\right]-r_{f} \boldsymbol{\iota}\right]\left[\mathbb{E}_{0}\left[\mathbf{r}_{r s, 1}\right]-r_{f} \boldsymbol{\iota}\right]^{T}\right) \boldsymbol{\alpha}_{r, 0} \\
& -\frac{1}{2} \boldsymbol{\alpha}_{r, 0}^{T} \operatorname{diag}\left(\left[\mathbb{E}_{0}\left[\mathbf{r}_{r s, 1}\right]-r_{f} \boldsymbol{\iota}\right]\left[\mathbb{E}_{0}\left[\mathbf{r}_{r s, 1}\right]-r_{f} \boldsymbol{\iota}\right]^{T}\right) \boldsymbol{\alpha}_{r, 0}-\frac{\tau_{r}}{2} \boldsymbol{\alpha}_{r, 0}^{T} \operatorname{Var}_{0}\left[\mathbf{r}_{r s, 1}\right] \boldsymbol{\alpha}_{r, 0}
\end{aligned}
$$

by choice of $\boldsymbol{\alpha}_{r, 0}$ for which the first-order condition is in the main text.

In the case of financial speculators, we write the budget constraint (7) as:

$$
w_{s, 1} \approx w_{s, 0}+r_{s p, 1}
$$

with:

$$
r_{s p, 1} \equiv r_{f}+\ln \left(1+\alpha_{s 1,0}\left(e^{p_{1}+c_{g, 1}-f_{0}^{1}-r_{f}}\right)+\alpha_{s 2,0}\left(e^{r_{e, 1}-r_{f}}-1\right)\right)
$$

Taking a second-order approximation of $r_{s p, 1}$ with respect to $\mathbf{r}_{s s, 1}$ about $\mathbf{0}$ we have:

$$
\begin{aligned}
& r_{s p, 1} \approx r_{f}+\frac{1}{1+\alpha_{s 1,0}}\left(\mathbf{r}_{s s, 1}-r_{f} \boldsymbol{\iota}\right) \boldsymbol{\alpha}_{s, 0}+\frac{1}{2\left(1+\alpha_{s 1,0}\right)^{2}} \operatorname{diag}\left(\left[\mathbb{E}_{0}\left[\mathbf{r}_{s s, 1}\right]-r_{f} \boldsymbol{\iota}\right]\left[\mathbb{E}_{0}\left[\mathbf{r}_{s s, 1}\right]-r_{f} \boldsymbol{\iota}\right]^{T}\right) \boldsymbol{\alpha}_{s, 0} \\
& -\frac{1}{2\left(1+\alpha_{s 1,0}\right)^{2}} \boldsymbol{\alpha}_{s, 0}^{T}\left[\mathbb{E}_{0}\left[\mathbf{r}_{s s, 1}\right]-r_{f} \iota\right]\left[\mathbb{E}_{0}\left[\mathbf{r}_{s s, 1}\right]-r_{f} \boldsymbol{\iota}\right]^{T} \boldsymbol{\alpha}_{s, 0}
\end{aligned}
$$

such that:

$$
\begin{aligned}
& \mathbb{E}_{0}\left[r_{s p, 1}\right] \approx r_{f}+\frac{1}{\left(1+\alpha_{s 1,0}\right)}\left(\mathbb{E}_{0} \mathbf{r}_{s s, 1}-r_{f} \boldsymbol{\iota}\right) \boldsymbol{\alpha}_{s, 0} \\
& +\frac{1}{2\left(1+\alpha_{s 1,0}\right)} \operatorname{diag}\left(\operatorname{Var}_{0}\left[\mathbf{r}_{s s, 1}\right]\right) \boldsymbol{\alpha}_{s, 0}+\frac{1}{2\left(1+\alpha_{s 1,0}\right)} \operatorname{diag}\left(\left[\mathbb{E}_{0}\left[\mathbf{r}_{s s, 1}\right]-r_{f} \iota\right]\left[\mathbb{E}_{0}\left[\mathbf{r}_{s s, 1}\right]-r_{f} \iota\right]^{T}\right) \boldsymbol{\alpha}_{s, 0} \\
& -\frac{1}{2\left(1+\alpha_{s 1,0}\right)^{2}} \boldsymbol{\alpha}_{s, 0}^{T} \operatorname{Var}_{0}\left[\mathbf{r}_{s s, 1}\right] \boldsymbol{\alpha}_{s, 0}-\frac{1}{2\left(1+\alpha_{s 1,0}\right)^{2}} \boldsymbol{\alpha}_{r, 0}^{T}\left[\mathbb{E}_{0}\left[\mathbf{r}_{s s, 1}\right]-r_{f} \boldsymbol{\iota}\right]\left[\mathbb{E}_{0}\left[\mathbf{r}_{s s, 1}\right]-r_{f} \boldsymbol{\iota}\right]^{T} \boldsymbol{\alpha}_{s, 0}
\end{aligned}
$$

and

$$
\operatorname{Var}_{0}\left[r_{s p, 1}\right] \approx \frac{1}{\left(1+\alpha_{s 1,0}\right)^{2}} \boldsymbol{\alpha}_{s, 0}^{T} \operatorname{Var}_{0}\left[\mathbf{r}_{s s, 1}\right] \boldsymbol{\alpha}_{s, 0}
$$

The rest of the steps towards the first-order solution are as in the case of the physical speculators. 


\section{B Appendix: Useful expressions}

In order to solve for the model numerically, the following expressions are useful:

$$
\begin{aligned}
& \mathbb{E}_{0}\left[P_{1}\right]=A_{1} Q_{0}^{-\eta} v_{1,0} \\
& \mathbb{E}_{0}\left[R_{e, 1}\right]=v_{2,0} \\
& \operatorname{Var}_{0}\left[P_{1}\right]=A_{1}^{2} Q_{0}^{-2 \eta} v_{11,0} \\
& \operatorname{Var}_{0}\left[R_{e, 1}\right]=v_{22,0} \\
& \operatorname{Cov}_{0}\left[P_{1}, R_{e, 1}\right]=A_{1} Q_{0}^{-\eta} v_{12,0} \\
& \operatorname{Corr}_{0}\left[P_{1}, R_{e, 1}\right]=\frac{\left(e^{\sigma_{p r e}}-1\right)}{\left(\left(e^{\sigma_{r e}^{2}}-1\right)\left(e^{\sigma^{2}}-1\right)\right)^{0.5}}
\end{aligned}
$$

where:

$$
\begin{aligned}
& v_{1,0} \equiv e^{\mu_{1}+\frac{\sigma^{2}}{2}} \\
& v_{2,0} \equiv e^{\left(1-\rho_{r e}\right) \mu_{r e, 1}+\rho_{r e} r_{e, 0}+\frac{\sigma_{r e}^{2}}{2}} \\
& v_{11,0} \equiv e^{2 \mu_{1}+\sigma^{2}}\left(e^{\sigma^{2}}-1\right) \\
& v_{12,0} \equiv e^{\mu_{1}+\left(1-\rho_{r e}\right) \mu_{r e, 1}+\rho_{r e} r_{e, 0}+\frac{\sigma^{2}}{2}+\frac{\sigma_{r e}^{2}}{2}}\left(e^{\sigma_{p r e}}-1\right) \\
& v_{22,0} \equiv e^{2\left(1-\rho_{r, e}\right) \mu_{r e, 1}+2 \rho_{r, e} r_{e, 0}+\sigma_{r e}^{2}}\left(e^{\sigma_{r e}^{2}}-1\right)
\end{aligned}
$$

and:

$$
\begin{aligned}
& \mu_{1} \equiv-\frac{\left(1-\rho_{g}\right) \mu_{g, 1}+\rho_{g} g_{0}}{\theta+\omega \varsigma}+\frac{\varsigma\left(\left(1-\rho_{y}\right) \mu_{y, 1}+\rho_{y} y_{0}\right)}{\theta+\omega \varsigma} \\
& \sigma^{2} \equiv(\theta+\omega \varsigma)^{-2} \sigma_{g}^{2}+\left(\frac{\varsigma}{\theta+\omega \varsigma}\right)^{2} \sigma_{y}^{2} \\
& \sigma_{\text {pre }} \equiv-\frac{\sigma_{g r e}}{\theta+\omega \varsigma}+\frac{\varsigma \sigma_{y r e}}{\theta+\omega \varsigma}
\end{aligned}
$$


Also:

$$
\begin{aligned}
& \mathbb{E}_{0}\left[p_{1}\right]=\frac{\varsigma}{\theta+\omega \varsigma} \gamma_{1}-\eta q_{0}+\mu_{1} \\
& \mathbb{E}_{0}\left[y_{1}\right]=\rho_{y} \ln y_{0}+\left(1-\rho_{y}\right) \mu_{y, 1} \\
& \mathbb{E}_{0}\left[x_{1}\right]=\gamma_{1}+\mathbb{E}_{0}\left[y_{1}\right]-\omega \mathbb{E}_{0}\left[p_{1}\right] \\
& \operatorname{Var}_{0}\left[p_{1}\right]=\sigma^{2} \\
& \operatorname{Cov}_{0}\left[y_{1}, p_{1}\right]=\frac{\varsigma}{\theta+\omega \varsigma} \sigma_{y}^{2} \\
& \operatorname{Var}_{0}\left[x_{1}\right]=\sigma_{y}^{2}+\omega^{2} \sigma^{2}-2 \omega \operatorname{Cov}_{0}\left[y_{1}, p_{1}\right] \\
& \operatorname{Cov}_{0}\left[x_{1}, p_{1}\right]=\operatorname{Cov}_{0}\left[y_{1}, p_{1}\right]-\omega \sigma^{2} \\
& \text { and } \operatorname{Cov}_{0}\left[x_{1}, y_{1}\right]=\sigma_{y}^{2}-\omega \operatorname{Cov}_{0}\left[y_{1}, p_{1}\right]
\end{aligned}
$$

We can derive similar expressions for $X_{0}, D_{0}, \mathbb{E}_{0}\left[X_{1}\right]$, and $\operatorname{Var}_{0}\left[X_{1}\right]$ :

$$
\begin{aligned}
& X_{0}=Y_{0} \Gamma_{0} P_{0}^{-\omega} \\
& D_{0}=Y_{0}^{\varsigma} \Gamma_{0}^{\varsigma} P_{0}^{-\omega \varsigma} Q_{0}^{1-\varsigma}
\end{aligned}
$$

and:

$$
\begin{aligned}
& \mathbb{E}_{0}\left[X_{1}\right]=\Gamma_{1}^{1-\frac{\omega \varsigma}{\theta+\omega \varsigma}} e^{\left(1-\rho_{y}\right) \mu_{y, 1}+\rho_{y} y_{0}-\omega \mu_{1}+\left(\frac{\omega}{(\theta+\omega \varsigma)}\right)^{2} \frac{\sigma_{g}^{2}}{2}+\left(\frac{\omega \varsigma}{\theta+\omega \varsigma}\right)^{2} \frac{\sigma_{y}^{2}}{2}} \\
& \mathbb{E}_{0}\left[D_{1}\right]=\left(Q_{0}\right)^{-(1-\varsigma)} \Gamma_{1}^{\varsigma\left(1-\frac{\omega \varsigma}{\theta+\omega \varsigma}\right)} e^{\varsigma\left(\left(1-\rho_{y}\right) \mu_{y, 1}+\rho_{y} y_{0}\right)-\varsigma \omega \mu_{1}+\left(\frac{\varsigma}{(\theta+\omega \varsigma)}\right)^{2} \frac{\sigma_{g}^{2}}{2}+\left(\frac{\omega \varsigma}{\theta+\omega \varsigma}\right)^{2} \frac{\sigma_{y}^{2}}{2}} \\
& \operatorname{Var}_{0}\left[X_{1}\right]=\Gamma_{1}^{2\left(1-\frac{\omega \varsigma}{\theta+\omega \varsigma}\right)} e^{2\left(1-\rho_{y}\right) \mu_{y, 1}+2 \rho_{y} y_{0}-2 \omega \mu_{1}+\left(\frac{\omega}{(\theta+\omega \varsigma)}\right)^{2} \sigma_{g}^{2}+\left(\frac{\omega \varsigma}{\theta+\omega \varsigma}\right)^{2} \sigma_{y}^{2}}\left(e^{\left(\frac{\omega}{(\theta+\omega \varsigma)}\right)^{2} \sigma_{g}^{2}+\left(\frac{\omega \varsigma}{\theta+\omega \varsigma}\right)^{2} \sigma_{y}^{2}}-1\right)
\end{aligned}
$$

\section{Appendix: The distribution of next-period consumption}

Following Kmenta (1967), a second-order approximation to the log of aggregate consumption (equation 11) about $\omega=1$ is:

$$
c_{c, 1} \approx\left(\frac{\Gamma_{1}^{\frac{1}{\omega}}}{1+\Gamma_{1}^{\frac{1}{\omega}}}\right) x_{1}+\left(\frac{1}{1+\Gamma_{1}^{\frac{1}{\omega}}}\right) y_{1}-\frac{1}{2} \frac{1-\omega}{\omega} \frac{\Gamma_{1}^{\frac{1}{\omega}}}{\left(1+\Gamma_{1}^{\frac{1}{\omega}}\right)^{2}}\left(x_{1}-y_{1}\right)^{2}
$$

As $x_{1}-y_{1}$ is normally distributed with conditional mean $\gamma_{1}-\omega \mathbb{E}_{0}\left[p_{1}\right]$ and conditional 
variance $\omega^{2} \operatorname{Var}_{0}\left[p_{1}\right]$, then $\frac{\left(x_{1}-y_{1}\right)^{2}}{\omega^{2} \operatorname{Var}_{0}\left[p_{1}\right]}$ follows a non-central chisquared distribution with conditional mean $1+\frac{\left(\mathbb{E}_{0}\left[x_{1}-y_{1}\right]\right)^{2}}{\operatorname{Var}_{0}\left[x_{1}-y_{1}\right]}=1+\frac{\left(\gamma_{1}-\omega \mathbb{E}_{0} p_{1}\right)^{2}}{\omega^{2} \operatorname{Var}_{0}\left[p_{1}\right]}$ and conditional variance $2\left(1+2\left(\frac{\left(\mathbb{E}_{0}\left[x_{1}-y_{1}\right]\right)^{2}}{\operatorname{Var}_{0}\left[x_{1}-y_{1}\right]}\right)\right)=$ $2\left(1+2\left(\frac{\left(\gamma_{1}-\omega \mathbb{E}_{0} p_{1}\right)^{2}}{\omega^{2} \operatorname{Var}_{0}\left[p_{1}\right]}\right)\right)$. To calculate the conditional covariances of $\left(x_{1}-y_{1}\right)^{2}$ with $x_{1}$ and $y_{1}$, we note that by Stein's lemma, if $x_{1}$ and $x_{1}-y_{1}$ are (conditionally) jointly normally distributed and $\left\|2\left(x_{1}-y_{1}\right)\right\|<\infty$, then:

$$
\operatorname{Cov}_{0}\left[x_{1},\left(x_{1}-y_{1}\right)^{2}\right]=2 \mathbb{E}_{0}\left[x_{1}-y_{1}\right] \operatorname{Cov}_{0}\left[x_{1}, x_{1}-y_{1}\right]
$$

and similarly for $x_{1}$ and $x_{1}-y_{1}$.

Therefore:

$$
\begin{aligned}
& \mathbb{E}_{0}\left[c_{1}^{c}\right]=\left(\frac{\Gamma_{1}^{\frac{1}{\omega}}}{1+\Gamma_{1}^{\frac{1}{\omega}}}\right) \mathbb{E}_{0}\left[x_{1}\right]+\left(\frac{1}{1+\Gamma_{1}^{\frac{1}{\omega}}}\right) \mathbb{E}_{0}\left[y_{1}\right] \\
& -\frac{1}{2} \frac{1-\omega}{\omega} \frac{\Gamma_{1}^{\frac{1}{\omega}}}{\left(1+\Gamma_{1}^{\frac{1}{\omega}}\right)^{2}}\left(\mathbb{E}_{0}\left[\left(x_{1}-y_{1}\right)^{2}\right]\right) \\
& \text { and } \operatorname{Var}_{0}\left[c_{1}^{c}\right]=\mathbf{V}_{1} \mathbf{V}_{2} \mathbf{V}_{1}^{T}
\end{aligned}
$$

where:

$$
\begin{aligned}
& \mathbf{V}_{2} \equiv \mathbb{E}_{0}\left[\mathbf{z}_{1} \mathbf{z}_{1}^{T}-\mathbb{E}_{0}\left[\mathbf{z}_{1}\right] \mathbb{E}_{0}\left[\mathbf{z}_{1}\right]^{T}\right] \\
& \mathbf{V}_{1}=\left[\begin{array}{llll}
\left(\frac{\Gamma_{1}^{\frac{1}{\omega}}}{1+\Gamma_{1}^{\frac{1}{\omega}}}\right) & \left(\frac{1}{1+\Gamma_{1}^{\frac{1}{\omega}}}\right) & -\frac{(1-\omega)}{2 \omega} \frac{\Gamma_{1}^{\frac{1}{\omega}}}{\left(1+\Gamma_{1}^{\frac{1}{\omega}}\right)^{2}}
\end{array}\right]
\end{aligned}
$$

and:

$$
\mathbf{z}_{1} \equiv\left[x_{1}, y_{1},\left(x_{1}-y_{1}\right)^{2}\right]
$$




\section{References}

Viral V. Acharya, Lars A. Lochstoer, and Tarun Ramadorai. Limits to arbitrage and hedging: Evidence from commodity markets. NBER Working Papers 16875, National Bureau of Economic Research, Inc, March 2011. URL http://ideas.repec.org/p/nbr/nberwo/16875. html.

Ron Alquist and Lutz Kilian. What do we learn from the price of crude oil futures? Journal of Applied Econometrics, 25(4):539-573, 2010. URL http://ideas.repec.org/a/jae/japmet/ v25y2010i4p539-573.html.

Ron Alquist, Lutz Kilian, and Robert J. Vigfusson. Forecasting the price of oil. CEPR Discussion Papers 8388, C.E.P.R. Discussion Papers, May 2011. URL http://ideas.repec.org/p/cpr/ ceprdp/8388.html.

Parantap Basu and William T. Gavin. What explains the growth in commodity derivatives? The Federal Reserve Bank of St. Louis Review, 93(1):37-48, Jan 2011. URL http://ideas. repec.org/a/fip/fedlrv/y2011ijanp37-48nv.93no.1.html.

Christiane Baumeister and Gert Peersman. The role of time-varying price elasticities in accounting for volatility changes in the crude oil market. Working Papers 11-28, Bank of Canada, Nov 2011. URL http://ideas.repec.org/p/bca/bocawp/11-28.html.

Geert Bekaert, Marie Hoerova, and Marco Lo Duca. Risk, uncertainty and monetary policy. Working Paper 16397, National Bureau of Economic Research, September 2010. URL http: //www.nber.org/papers/w16397.

Severin Borenstein and Ryan Kellogg. The incidence of an oil glut: Who benefits from cheap crude oil in the midwest? NBER Working Papers 18127, National Bureau of Economic Research, Inc, June 2012. URL http://ideas.repec.org/p/nbr/nberwo/18127.html.

Bahattin Büyükşahin and Michel. A. Robe. Does "paper oil" matter? energy market financialization and equity-commodity co-movements. Accepted Paper Series 1855264, SSRN, July 2011. URL http://ssrn. com/abstract=1855264.

John Y. Campbell, Yeung Lewis Chan, and Luis M. Viceira. A multivariate model of strategic asset allocation. Journal of Financial Economics, 67(1):41-80, January 2003. URL http: //ideas.repec.org/a/eee/jfinec/v67y2003i1p41-80.html. 
Jean-Pierre Danthine. Information, futures prices, and stabilizing speculation. Journal of Economic Theory, 17(1):79-98, February 1978. URL http://ideas.repec.org/a/eee/jetheo/ v17y1978i1p79-98.html.

Angus Deaton and Guy Laroque. Competitive storage and commodity price dynamics. Journal of Political Economy, 104(5):896-923, October 1996. URL http://ideas.repec.org/a/ucp/ jpolec/v104y1996i5p896-923.html.

Katherine Dusak. Futures trading and investor returns: An investigation of commodity market risk premiums. Journal of Political Economy, 81(6):1387-1406, Nov.-Dec. 1973. URL http: //ideas.repec.org/a/ucp/jpolec/v81y1973i6p1387-1406.html.

Erkko Etula. Broker-dealer risk appetite and commodity returns. Staff Reports 406, Federal Reserve Bank of New York, 2009. URL http://ideas.repec.org/p/fip/fednsr/406.html.

Eugene F Fama and Kenneth R French. Commodity futures prices: Some evidence on forecast power, premiums, and the theory of storage. Journal of Business, 60(1):55-73, January 1987. URL http://ideas.repec.org/a/ucp/jnlbus/v60y1987i1p55-73.html.

Bassam Fattouh, Lutz Kilian, and Lavan Mahadeva. The role of speculation in oil markets: What have we learned so far? CEPR Discussion Papers 8916, C.E.P.R. Discussion Papers, March 2012. URL http://ideas.repec.org/p/cpr/ceprdp/8916.html.

Bassam Fattouh and Lavan Mahadeva. OPEC: What difference has it made? Annual Review of Resource Economics, forthcoming.

Jeffrey A. Frankel. The effect of monetary policy on real commodity prices. Working Paper 12713, National Bureau of Economic Research, December 2006. URL http://www.nber.org/ papers/w12713.

Kenneth R. French. Detecting spot price forecasts in futures prices. The Journal of Business, 59(2):pp. S39-S54, 1986. ISSN 00219398. URL http://www.jstor.org/stable/2352781.

R.L. Gustafson. Carryover levels for grains: A method for determining amounts that are optimal under specified conditions. Technical Bulletin 1178, USDA, May 1958.

James D. Hamilton and Jing Cynthia Wu. Risk premia in crude oil futures prices. Working paper, University of Chicago Booth School of Business, May 2012. URL http://dss.ucsd. edu/ jhamilto/hw4.pdf 
Rögnvaldur Hannesson. Does speculation drive the price of oil? OPEC Energy Review, 36(2): 125-137, 2012. ISSN 1753-0237. URL http://dx.doi.org/10.1111/j.1753-0237.2011. $00207 . x$.

Harold Hotelling. The economics of exhaustible resources. Journal of Political Economy, 39(2): pp. 137-175, 1931. ISSN 00223808. URL http://www.jstor.org/stable/1822328.

Nicholas Kaldor. Speculation and economic stability. The Review of Economic Studies, 7(1):pp. 1-27, 1939. ISSN 00346527. URL http://www.jstor.org/stable/2967593.

John Maynard Keynes. A Treatise on Money: The Applied Theory of Money. London: Macmillan for the Royal Economic Society, December 1931.

Lutz Kilian. Not all oil price shocks are alike: Disentangling demand and supply shocks in the crude oil market. American Economic Review, 99(3):1053-69, June 2009. URL http: //ideas.repec.org/a/aea/aecrev/v99y2009i3p1053-69.html.

Lutz Kilian and Dan Murphy. The role of inventories and speculative trading in the global market for crude oil. CEPR Discussion Papers 7753, C.E.P.R. Discussion Papers, March 2010. URL http://ideas.repec.org/p/cpr/ceprdp/7753.html.

Jan Kmenta. On estimation of the ces production function. International Economic Review, 8 (2):pp. 180-189, 1967. ISSN 00206598. URL http://www.jstor.org/stable/2525600.

Abraham Lioui and Patrice Poncet. Dynamic Asset Allocation with Forwards and Futures. Accepted paper series, SSRN, 2005.

Robert E. Lucas. Macroeconomic priorities. American Economic Review, 93(1):1-14, March 2003. URL http://ideas.repec.org/a/aea/aecrev/v93y2003i1p1-14.html.

Michael W. Masters. Testimony before the committee on homeland security and governmental affairs, united states senate. Congress, US Congress, 2008. URL http://www.hsgac .senate. gov/imo/media/doc/052008Masters.pdf?attempt=2.

David M. Newbery and Joseph E. Stiglitz. The Theory of Commodity Price Stabilization: A Study in the Economics of Risk. Clarendon Press, Cambridge, UK, 1981. 
Luboš Pástor and Robert F. Stambaugh. Are stocks really less volatile in the long run? Journal of Finance, 67(2):431-478, 04 2012. URL http://ideas.repec.org/a/bla/jfinan/ v67y2012i2p431-478.html.

Craig Pirrong. Commodity Price Dynamics: A Structural Approach. Cambridge University Press, New York, 2012.

Michael Plante and Jackson Thies. Commodity futures investing: method to the madness. Economic Letter: Insights from the Federal Reserve Bank of Dallas, 7(5):1-4, May 2012. URL http://ideas.repec.org/a/fip/feddel/y2012imaynv.7no.5.html.

Paul A. Samuelson. Proof that properly anticipated prices fluctuate randomly. Industrial Management Review, 6(2):41-49, Spring 1965. URL http://stevereads.com/papers_to_read/ proof_that_properly_anticipated_prices_fluctuate_randomly.pdf.

Annastiina Silvennoinen and Susan Thorp. Financialization, crisis and commodity correlation dynamics. Research Paper Series 267, Quantitative Finance Research Centre, University of Technology, Sydney, January 2010. URL http://ideas.repec.org/p/uts/rpaper/267. html.

Kenneth J. Singleton. Investor flows and the 2008 boom/bust in oil prices. Accepted Paper Series 1793449, SSRN, March 2011. URL http://ssrn.com/abstract=1793449.

Ron P. Smith. Real-financial interactions in macro-finance models. Quantitative and Qualitative Analysis in Social Sciences, 3(1):pp. 1-20, 2009. ISSN 17528925. URL http://www.qass. org.uk/2009/Vol_1/paper1.pdf.

Jeremy C. Stein. Informational externalities and welfare-reducing speculation. Journal of Political Economy, 95(6):pp. 1123-1145, 1987. ISSN 00223808. URL http://www.jstor.org/ stable/1831115.

Ke Tang and Wei Xiong. Index investment and financialization of commodities. NBER Working Papers 16385, National Bureau of Economic Research, Inc, September 2010. URL http: //ideas.repec.org/p/nbr/nberwo/16385.html.

Lester G. Telser. Futures trading and the storage of cotton and wheat. Journal of Political Economy, 66:233, 1958. URL http://ideas.repec.org/a/ucp/jpolec/v66y1958p233.html. 
Stephen J. Turnovsky. The determination of spot and futures prices with storable commodities. Econometrica, 51(5):pp. 1363-1387, 1983. ISSN 00129682. URL http://www.jstor.org/ stable/1912279.

Jeffrey Williams. Futures markets: A consequence of risk aversion or transactions costs? Journal of Political Economy, 95(5):pp. 1000-1023, 1987. ISSN 00223808. URL http://www.jstor. org/stable/1833126.

Holbrook Working. Theory of the Inverse Carrying Charge in Futures Markets. Journal of Farm Economics, 30(1), 1948. ISSN 10711031. URL http://dx.doi.org/10.2307/1232678.

Holbrook Working. The Theory of Price of Storage. The American Economic Review, 39(6), 1949. ISSN 00028282. URL http://dx.doi.org/10.2307/1816601. 